CHARACTERIZATION AND REPRODUCIBILITY OF PETROLEUM PITCHES

W. E. Smith

O. J. Horne, Jr

B. Napier, Jr 


\section{DISCLAIMER}

This report was prepared as an account of work sponsored by an agency of the United States Government. Neither the United States Government nor any agency Thereof, nor any of their employees, makes any warranty, express or implied, or assumes any legal liability or responsibility for the accuracy, completeness, or usefulness of any information, apparatus, product, or process disclosed, or represents that its use would not infringe privately owned rights. Reference herein to any specific commercial product, process, or service by trade name, trademark, manufacturer, or otherwise does not necessarily constitute or imply its endorsement, recommendation, or favoring by the United States Government or any agency thereof. The views and opinions of authors expressed herein do not necessarily state or reflect those of the United States Government or any agency thereof. 


\section{DISCLAIMER}

Portions of this document may be illegible in electronic image products. Images are produced from the best available original document. 
Reference to a company or product name does not imply approval or recommendation of the product by Union Carbide Corporation or the U.S. Atomic Energy Commission to the exclusion of others that may meet specifications.

Printed in the United States of America. Available from

National Technical Information Service

U.S. Department of Commerce

5285 Port Royal Road, Springfield, Virginia 22151

Price: Printed Copy \$4.00; Microfiche $\$ 1.45$

This report was prepared as an account of work sponsored by the United States Government. Neither the United States nor the United States Atomic Energy Commission, nor any of their employees, nor any of their contractors, subcontractors, or their employees, makes any warranty, express or implied, or assumes any legal liability or responsibility for the accuracy, completeness or usefulness of any information, apparatus, product or process disclosed, or represents that its use would not infringe privately owned rights. 


\title{
CHARACTERIZATION AND REPRODUCIBILITY OF PETROLEUM PITCHES
}

\author{
W. E. Smith \\ O. J. Horne, Jr \\ B. Napier, Jr
}

Oak Ridge Y.12 Plant

P.O. Box Y, Oak Ridge. Tennessee 37830

Date Issued - March 1, 1974

Prepared for the U.S. Atomic Energy Commission Under U.S. Government Contract W.7405eng.26 


\begin{abstract}
An analytical study was designed to establish the reproducibility of a petroleum pitch system as a function of the sampling period, and to obtain information on the molecular structures and compositions of these materials. Samples of petroleum pitch and the feedstocks from which the pitches were made were received monthly from the vendor during a 12-month sampling period, and were subsequently analyzed along with control samples. Properties obtained included molecular weight and distribution analyses, softening points, viscosities, benzene insolubles, elemental compositions, and coke vields. Month-to-month variability in the properties of the feedstock was greater than that observed for the corresponding pitch samples, indicating that the pitch-producing process has a leveling effect on the precursor property differences.

Studies on molecular structures present in pilch and feedstock materials were made using nuclear magnetic resonance techniques which allowed an estimation of sizes and compositions of aromatic and aliphat/c groups, and the number of alkyl substituents per molecule. Models were suggested that fit these average properties.
\end{abstract}




\section{CONTENTS}

SUMMARY

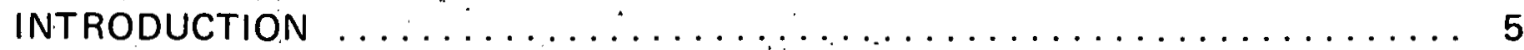

CHARACTERIZATION AND REPRODUCIBILITY OF PETROLEUM PITCHES $\ldots . .7$

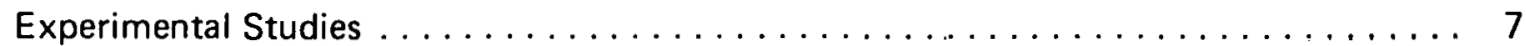

Materials .......................... 7

Methods ................................. 7

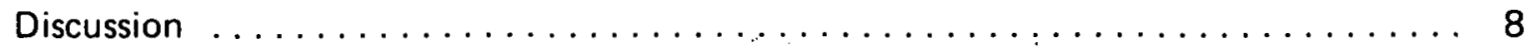

Comparative Properties of Petroleum Products $\ldots \ldots \ldots \ldots \ldots \ldots \ldots \ldots$

Characterization Studies Using Nuclear Magnetic Resonance Techniques . . . . . . . 13

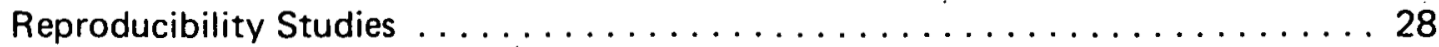

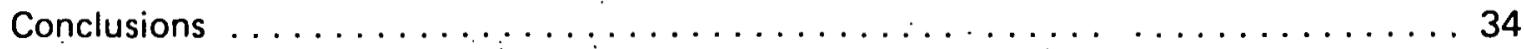

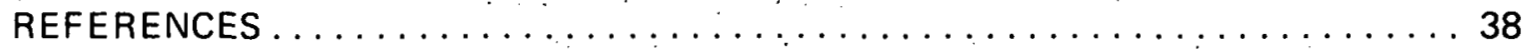

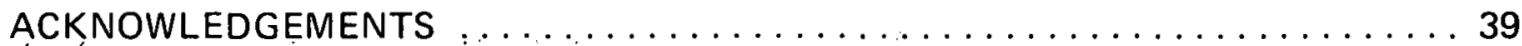

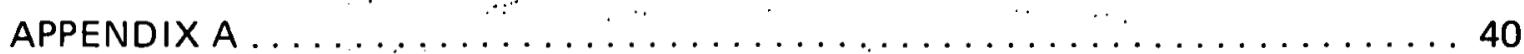

Procedure for Removing Insolubles from Pitches $\ldots \ldots \ldots \ldots \ldots \ldots \ldots \ldots \ldots$

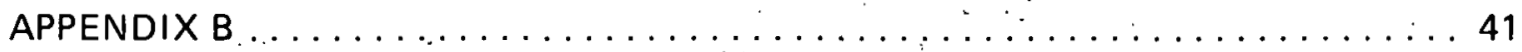

Standardized Instrument Conditions for Nuclear Magnetic Resonance Analyses . . . . 41

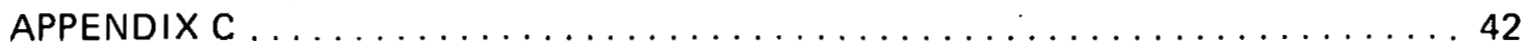

Calculations Used for Evaluating Nuclear Magnetic Resonance Data . . . . . . . . . 42 


\section{SUMMARY}

Efforts to determine the reproducibility and composition of various petroleum-derived materials consisted of analyzing, during a 12 -month study, petroleum feedstocks and derived pitches, both of which were received monthly from the vendor. Measured properties included: (1) molecular weights and distributions, (2) softening points, (3) viscosities, (4) benzene insolubles, (5) elemental compositions, (6) coke yields, and (7) proton distributions.

Calculated properties included: (1) carbon distributions between saturated and aromatic, bridging and nonbridging, and acyclic and naphthenic groups; (2) size and composition of the aromatic groups; (3) slze and composition of the alkyl substituents; (4) number of alkyl substituents per molecule, and (5) number of naphthenic rings per molecule.

Primary conclusions reached from the study were:

1. The month-to-month variability of Type A-240 petroleum pitch was less than that measured for feedstocks, indicating that the pitch-production process has a leveling effect on the property variations of the feedstock samples.

2. Desulfurization (to $\sim 0.1 \%$ ) of Type A-240 petroleum pitch also reduces the oxygen levels by approximately one-third and metal contents by a factor of 5 to 10 , and is accompanied by the opening of rings other than those containing sulfur.

3. The average properties of petroleum feedstocks suggest a molecular model comprised of three fused aromatic rings will, three alkyl substituents per molecule, while those of Type A-170 pitch suggest a model containing six to seven fused aromatic rings with 3.3 alkyl substituents per molecule. 


\section{INTRODUCTION}

This report describes an analytical study designed to determine the reproducibility of a petroleum pitch as a function of sampling period and to determine structural changes that accompany: (1) conversion of feedstock to pitch, and (2) desulfurization of these pitch products. Samples of petroleum products were received monthly from the vendor during a one-year sampling program, and were subsequently subjected to analysis. Discussed in this report are a general comparative property study of all product types analyzed, structural characterization using NMR (nuclear magnetic resonance), and reproducibility studies. A previous report in this series discussed the thermal stabilities of these materials and described the types of carbon that may be derived. (1)

Discovery and implementation of pitches as bonding agents is recorded in some of the earliest known documents, and their usage in all probability long predates recorded history. Current usage continues to reflect the natural abundance (though rapidly depleting) and desirable properties of pitch materials. Numerous industries have been built around such applications as road surfacing, roofing materials, and various adhesive and sealant formulations.

One application in which pitch materials have been used is as a binder in the fabrication of composite structures which can subsequently be pyrolyzed to yield carbon. Such fabrication schemes place emphasis on pitch materials that exhibit appropriate properties both as plastics at fabrication temperatures and as ceramic-type materials after carbonization. Since the properties of the latter are quite dependent on the characterisistics of the raw material and the chemical and mechanical events that accompany carbonization, the fabrications engineer becomes interested in such subjects as pitch properties, impurity contents, coke yields, and volume yields as they relate to the mechanical and electrical properties of the end product. To optimize and insure reproducibility of such a fabrication scheme, close control of both material and processing is required.

Though the use of pitch is an ancient art and represents a high-volume market today, characterization and control of pitches have not been emphasized since typical high-volume applications do not warrant such an emphasis. However, certain specialty applications require a high degree of characterization and control of starting materials, and it has been these users who continue to support eftorts designed for that purpose. Fabricators of specialty items, in general, face less cost restraints and have a higher degree of precision in design and fabrication efforts. However, a fabrications engineer can take little satisfaction in computer-controlled precision when the starting materials remain quite variable.

Pitch from natural sources represents a complex mixture of structures and varies in composition with the location of the source and with the methods used to extract the pitch. The latter can be slandardized, but must also compensate for variations in the source if a reproducible pitch is to be made. 
As part of a continuing study at the Oak Ridge $Y-12$ Plant ${ }^{(a)}$ on precursors to carbon, this report evaluates the composition and reproducibility of commercial petroleum pitch products from the Ashland Oil Company, Ashland, Kentucky. The pitches were isolated as distillate fractions from a cracking operation. Such an approach to pitch production reduces metallic impurities and represents an effort toward better control of pitch properties. By agreement with the vendor, a sampling schedule was arranged whereby the pitch production stream would be sampled each month and a specific pitch type (A-240) would be shipped for evaluation along with the feedstock used to make the pitch. Analyses of both the pitch and feedstock were designed to determine any month-to-month variability of these products. A total of $13 \mathrm{pitch} /$ feedstock sample pairs were received during a 12-month sampling period, and 10 of the 13 sample pairs were analyzed in this phase of the prograrin. Eight of the sample pairs corresponded to consecutive samples taken monthly from January through August 1972. During the month of June, a second samplo pair was taken which corresponded to a significant change in the feedstock source. The final sample pair included in the study was taken in early January 1973, Just afler significant maintenance was completed on the pitch production facilities.

Characterization studies on the molecular composition of specific pitch and feedstock samples were conducted. Included in this study were a low-sulfur form of Type A-240 pitch and a second pitch designated as Type A-170. The latter material is a lower-temperature fraction than Type A-240 pitch; and, as a result, exhibits the expected property differences.

(a) Operated by the Union Carbide Corporation's Nuclear Division for the US Atomic Energy Commission. 


\section{CHARACTERIZATION AND REPRODUCIBILITY OF PETROLEUM PITCHES}

\section{EXPERIMENTAL STUDIES}

\section{Materials}

All petroleum materials used in this study were supplied by the Ashland Oil Company, Ashland, Kentucky. Samples of Type A-240 pitch, along with the petroleum feedstock used to prepare the pitch, were taken monthly from the pitch production stream and shipped to the Y-12 Plant for analysis. Single samples of Type A-170 pitch (A-170) and a low-sulfur form of Type A-240 pitch (A-240) were received for comparative studies. All feedstock samples were fluid and were analyzed as received. All pitch samples were powdered and dried, prior to analysis, for 20 hours at $25^{\circ} \mathrm{C}$ and under a vacuum of $<100 \mu \mathrm{m}$.

Methods

Descriptions of the analytical procedures used in this study are presented in the subsections that follow. Standard deviations for a number of methods were calculated from control samples that were included in the sampling schedule. (The calculated standard deviations are listed later as a part of Table 11.)

Softening Points - Softening points were determined by the ring-and-ball method, as per ASTM D-36-66. Visual observations of the melting processes involved use of a Fisher-Johns melting-point block.

Viscosities - Viscosities were measured by the Saybolt-Furol viscosimeter, as per ASTM D-88-56. Studies of viscosity as a function of temperature were conducted using a Brookfield RV.T viscosimeter with a recorder.

Average Molecular Weight - Average molecular weight data were obtained using a Hewlett-Packard Model 302: vapor pressure osmometer. Sucrose octaacetate was used as a standard. Prior to analysis, chloroform insolubles were removed by a standard procedure (see Appendix A). Samples were analyzed as tetrahydrofuran solutions; benzene insolubles were.determined as per ASTM D-2317.

Gel Permeation Chromatography - Gel permeation chromatography data were obtained using Waters Associates Model $200 \mathrm{GPC}$ with columns packed. with Styragel (styrene-divinylbenzene polymer). Prior to analysis, chloroform insolubles were removed by a standard procedure (see Appendix A). Samples were analyzed as tetrahydrofuran solutions.

Carbon and Hydrogen Contents - Carbon and hydrogen contents were determined by combustion in a carbon train using quantities of evolved carbon dioxide and water to calculate the carbon and hydrogen contents, respectively.

Oxygen and Nitrogen Contents - Oxygen and nitrogen contents were determined by neutron activation analysis using a Kaman Model 711 neutron generator and beryllium as a standard. 
Sulfur Content - Analysis for the sulfur content involved combustion in a bomb followed by a gravimetric determination of sulfur as barium sulfate.

Ash Content - Ash contents were determined by firing samples to $900^{\circ} \mathrm{C}$ in air and weighing the residuals.

Spectrographic Analysis-A semiquantitative spectrographic analysis of the pitch was performed using a Jarrell-Ash optical emission spectrograph. Results were reported as parts-per-million quantities of elemental constituents present in the as-received pitch.

Nuclear Magnetic Resonance Studies - Nuclear magnetic resonance (NMR) studies were conducted using a Bruker HFX-15 90-megahertz spectrometer. Tetramethylsilane was used as an internal standard. Samples were analyzed as five percent solutions in carbon tetrachloride. Other instrument conditions are listed in Appendix B. Calculations used In evaluating the NMR data are listed in Appendix C.

Coke Yield-Coke yields were determined by the Conradson method, as per ASTM D-189-65.

Thermal Analysis - Thermal analyses were conducted using a Mettler T6-1 vacuum thermal analyzer.

\section{DISCUSSION}

\section{Comparative Properties of Petroleum Products}

Properties of samples representing each of the various product types that were studied will be presented and discussed to familarize the reader with the materials and allow property comparisons between these materials. Emphasis during this phase of the study was given to property changes that accompany the production of pitch from feedstock and those that accompanv desulfurization. Included in this property list were: (1) a sample of the A-240 pitch, (2) the average properties of all A-240 samples studied, (3) a sample of feedstock, (4) the average properties of all feedstock samples studied, (5) an A.240 pitch which had been subjected to a desulfurization process, and (6) a sample of A-170 pitch. The feedstock listed was a precursor to the A-240 pitch sample listed. This pitch-feedstock combination was chosen because each was subjected to more detailed analysis, as will be presented in other parts of this report. Average properties of all feedstocks and A-240 pitch samples that were analyzed were listed as a better reference for comparisons than afforded by single samples of each. As previously stated, the pitch samples were collected as distillate fractions during preparation, with A-170 pitch representing the lower-temperature fraction. Though the feedstock sample listed was not used to prepare the A-240 low-sulfur pitch and the A-170 pitch sample listed, any of these pitch types can be derived from the same feedstock. The low-sulfur A-240 pitch was prepared by the vendor by subjecting stock A-240 pitch to a proprietary desulfurization process. Property data for the various product types are listed in Table 1.

Melting Properties - Petroleum pitches A-170 and A-240 are classified on the basis of their softening point data: The numbered notations $(240$ and 170$)$ are the softening points (in OF) that typify the respective pitch types (they correspond to approximately 116 and 
Table 1

COMPARATIVE PROPERTIES OF PETROLEUM-DERIVED MATERIAL

\begin{tabular}{|c|c|c|c|c|c|c|c|c|c|c|c|c|c|c|c|c|c|}
\hline \multirow[b]{2}{*}{$\begin{array}{c}\text { Sample } \\
\text { Nlımher }\end{array}$} & \multirow[b]{2}{*}{$\begin{array}{c}\text { Material } \\
\text { nessrintion } \\
\end{array}$} & \multirow{2}{*}{$\begin{array}{c}\text { Softening } \\
\text { Point } \\
(\circ \mathrm{C}) \\
\end{array}$} & \multirow[b]{2}{*}{$\begin{array}{c}\text { Viscosity (1) } \\
\text { (sec) }\end{array}$} & \multirow{2}{*}{$\begin{array}{c}\text { Average } \\
\text { Molecular } \\
\text { Weight }\end{array}$} & \multirow{2}{*}{$\begin{array}{c}\text { Benzene } \\
\text { Insolubles } \\
(\%) \\
\end{array}$} & \multicolumn{4}{|c|}{ Composition of Molecular Size Distributions (2) } & \multirow{2}{*}{$\begin{array}{c}\text { Carbon } \\
\text { Content } \\
(\%)\end{array}$} & \multirow{2}{*}{$\begin{array}{c}\text { Hydrogen } \\
\text { Content } \\
(\%)\end{array}$} & \multirow{2}{*}{$\begin{array}{c}\text { Oxygen } \\
\text { Content } \\
(\%)\end{array}$} & \multirow{2}{*}{$\begin{array}{c}\text { Sulfur } \\
\text { Content } \\
(\%)\end{array}$} & \multirow{2}{*}{$\begin{array}{c}\text { Ash } \\
\text { Content } \\
(\%) \\
\end{array}$} & \multirow[b]{2}{*}{$H_{A}^{*}(3)$} & \multirow[b]{2}{*}{$n^{(3)}$} & \multirow{2}{*}{$\begin{array}{l}\text { Coke } \\
\text { Yield } \\
\text { (\%) }\end{array}$} \\
\hline & & & & & & $\begin{array}{c}\text { Fraction } 1 . \\
(\%)\end{array}$ & $\begin{array}{l}\text { Fraction } 2 \\
\text { (\%) }\end{array}$ & $\begin{array}{c}\text { Fraction } 3 \\
(\%)\end{array}$ & $\begin{array}{c}\text { Fraction } 4 \\
(50)\end{array}$ & & & & & & & & \\
\hline \multirow[t]{3}{*}{ RD-79P } & Feedstock & - & 327 & 301 & - & 13.8 & 43.1 & 24.4 & 18.7 & 89.77 & 8.99 & - & 0.67 & 0.08 & 0.23 & 3.0 & 5.1 \\
\hline & Average of all & & & & & & & & & & & & & & & & \\
\hline & Feedstock Samples & - & $232(9)^{(4)}$ & $287(4)$ & $\cdot$ & $13.8(9)$ & 48.2(9) & $23.8(9)$ & $14.2(9)$ & $89.87(4)$ & $8.58(4)$ & - & $0.87(9)$ & $0.08(9)$ & $0.26(9)$ & $2.8(9)$ & - \\
\hline \multirow[t]{3}{*}{ RD-80P } & A.240 Pitch & 114.4 & 53 & 478 & 6.4 & 8.7 & 27.9 & 28.6 & 34.8 & 93.34 & 5.42 & 0.20 & 0.86 & 0.09 & 0.57 & 1.22 & 49.0 \\
\hline & Average of all & & & & & & & & & & & & & & & & \\
\hline & $\begin{array}{l}\text { A-240 Pitch } \\
\text { Samples }\end{array}$ & $112.0(10)$ & $60(9)$ & $479(10)$ & $5.0(10)$ & $9.2(10)$ & $25.9(10)$ & $27.5(10)$ & $37.5(10)$ & - & - & $0.22(10)$ & $1.04(10)$ & $0.13(10)$ & $0.57(10)$ & $1.22(10)$ & $47.5(10)$ \\
\hline \multirow[t]{3}{*}{ RD-72P } & A-240 Pitch & & & & & & & & & & & & & & & & \\
\hline & (low sulfur) & 110.9 & 55 & 482 & 4.2 & 13.5 & 26.2 & 29.8 & 30.6 & 94.53 & 5.90 & 0.07 & 0.11 & 0.02 & 0.54 & 1.52 & 51.3 \\
\hline & A-170 Pitch & 79.8 & 15 & 415 & 1.8 & 7.1 & 27.8 & 28.5 & 36.7 & 91.80 & 5.98 & 0.70 & 0.84 & 0.02 & 0.51 & 1.36 & 35.2 \\
\hline $\begin{array}{l}\text { (1) Meas } \\
\text { (2) Гract } \\
\text { (3) Dete } \\
\text { (4) Num }\end{array}$ & $\begin{array}{l}\text { ured in Saybolt-Furo } \\
\text { tions corrcspond to o } \\
\text { rmined from nuclear } \\
\text { bers in parentheses re }\end{array}$ & $\begin{array}{l}\text { I seconds. Fe } \\
\text { lution count } \\
\text { magnetic resc } \\
\text { epresent num }\end{array}$ & $\begin{array}{l}\text { edstocks were } \\
\text { rangos on gol } \\
\text { onance data, a } \\
\text { tbers of sampl }\end{array}$ & $\begin{array}{l}\text { measured at } \\
\text { permeatinn r. } \\
\text { s described it } \\
\text { es averaged. }\end{array}$ & $\begin{array}{l}t 25^{\circ} \mathrm{C} \text { and } \\
\text { hrnmatnorap } \\
\text { in Appendix }\end{array}$ & $\begin{array}{l}\text { pitches at } 20 \\
\text { phic scans (se } \\
\text { C. Symbol d }\end{array}$ & $\begin{array}{l}00 \mathrm{C} \text {. } \\
\text { ee Fiqure 2), } \\
\text { escription is }\end{array}$ & also given & Appendix $C$ & & & & & & $i$ & & \\
\hline
\end{tabular}


$77^{\circ} \mathrm{C}$, respectively). Thus, the data in Table 1 affirm these assignments and indicate little of no change in the softening point of A-240 pitch due to desulfurization. Differences for the A-240 pitch samples in Table 1 approximate the deviation experienced for the analytical method. All of the feedstock samples were liquid at room temperature.

Viscosities - Viscosity data were obtained at $25^{\circ} \mathrm{C}$ for feedstock materials and at $200^{\circ} \mathrm{C}$ for pitch materials using a Saybolt-Furo viscosimeter $A$ s indicatcd in Tablc 1 , no significant change in viscosity of the A-240 pitch occurred on desulfurization.

A sernnd part of the viscosity studies consisted of measuring changes in viscosity of A-170 and A-240 pitches with increasing temperature. These data, reported in Figure 1, describe essentially parallel curves, with the A-170 pitch having the lower viscosity at any given temperature. Comparative data indicate that the $A-170$ viscosities at 175 200 , and $250^{\circ} \mathrm{C}$ are, respectively, one eighth, one fifth, and one third those of the A-240 values.

Average Molecular Weights - Data obtained for the avcrage molecular weight studies

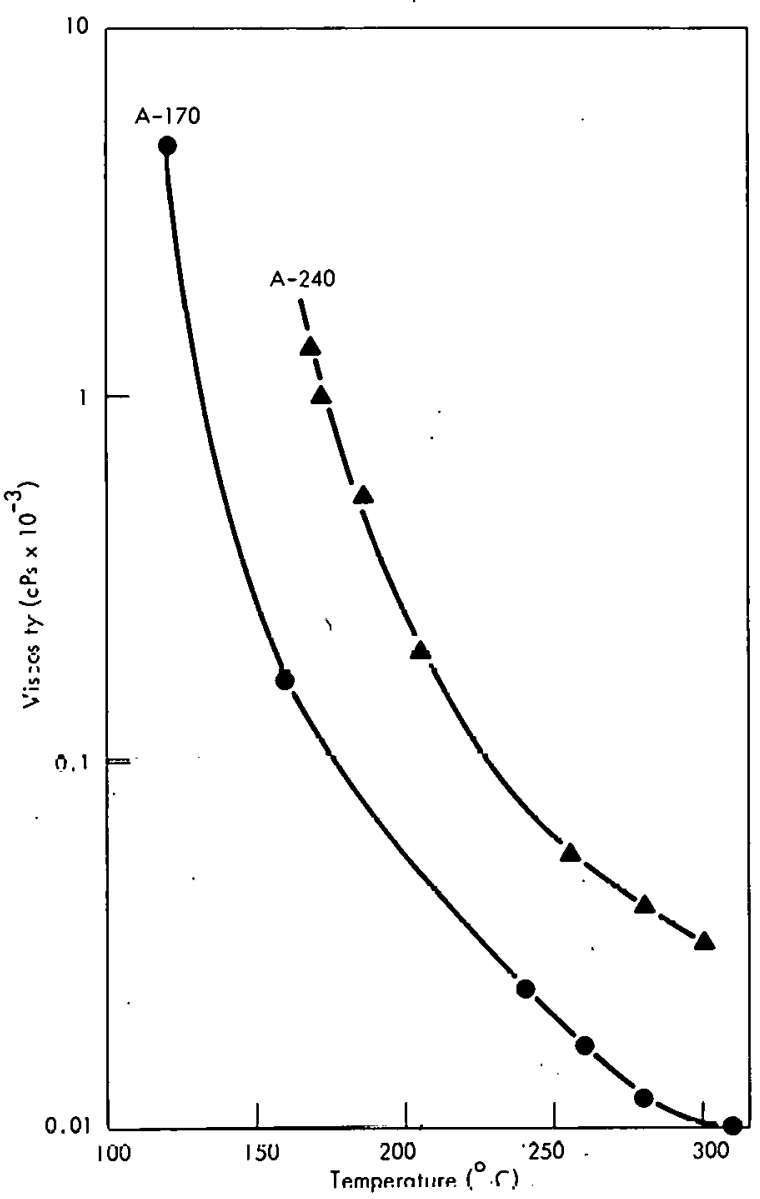

Figure 1. VISCOSITIES OF PITCH MATERIALS AS A FUNCTION OF THE TEMPERATURE.

correlated well with the property differences that were previously stated for these petroleum products. Typical values for the feedstocks approach 300 while those for A-240 pitches were just under 500. The single value (415) listed for the A-170 pitch was, as expected, intermediate between those two values. Again, the property difference noted he.tween Inw-s!!l fur ạnd stork. A.240 pitch samplec wac not significant, indicating little or no change in the averaye mulucular wight on desulfurlzation.

Benzene Insolubles - Benzene insoluble data were obtained on pitch samples unly, anu values for the A-240 pitcheE averaged just under five percent. Considering the ranige u values measured for the A-240 pitch samples, the value obtained for the low-sulfur sample (4.2\%) would not he considered significantly different from that of the storik smmplos. However, the value obtained for A-170 pitch $(1.8 \%)$ is significantly different and is in line with the other property differences previously discussed.

Molecular Distributions - Molecular-size distributions of the samples listed in Table 1 were studied using gel permeation chromatography (GPC) techniques. GPC scans of a A-240 pitr.h sample and its corresponding feedstock, as portrayed in Figure 2, are typical of these two product types. Evaluation of molecular distribution data consisted, in part, of dividing the distribution scan into four fractions and integrating the area under each fraction. These divisions are noted in Figure 2 and were identical for all samples analyzed during this 


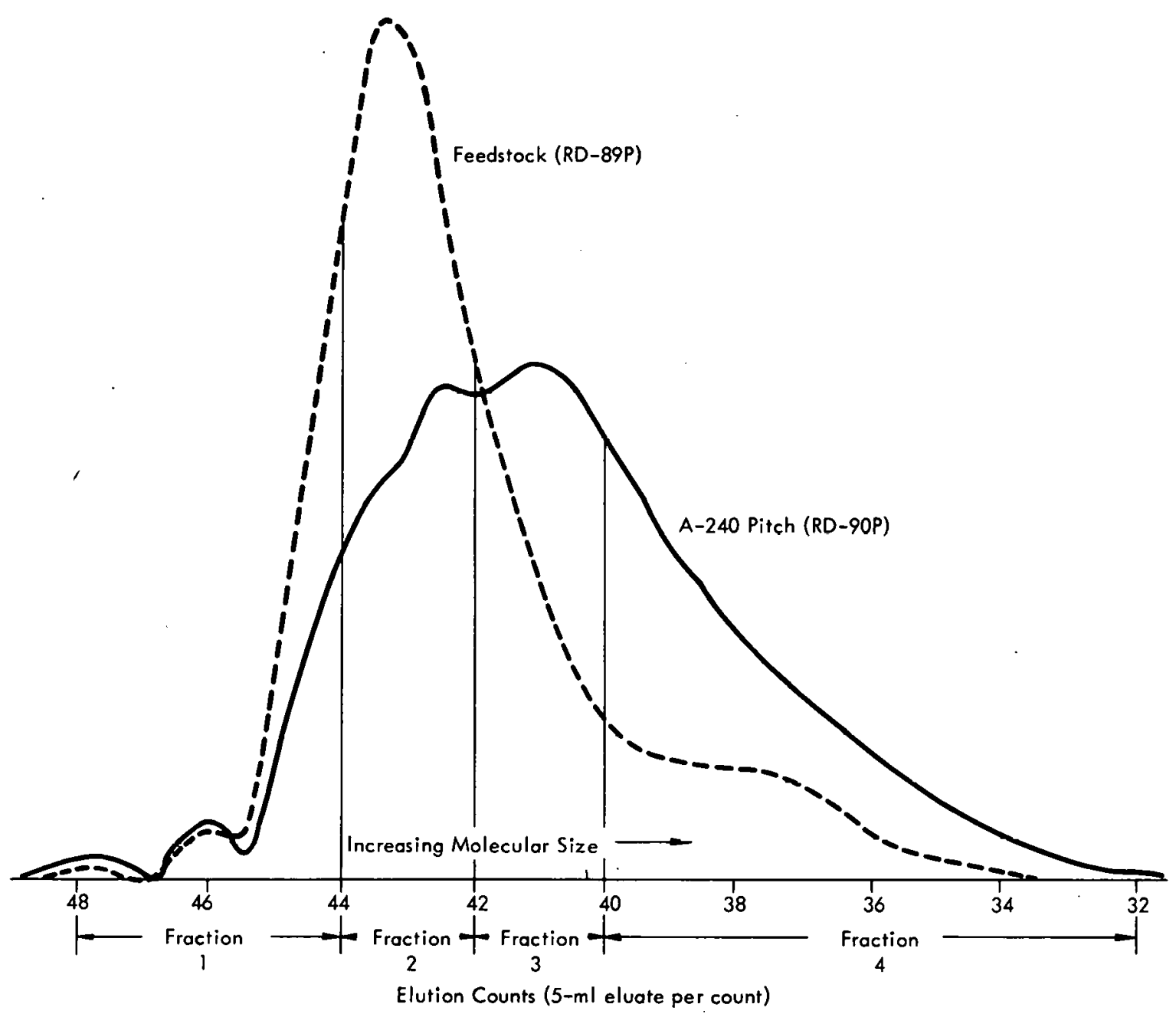

Figure 2. GEL PERMEATION CHROMATOGRAPHIC SCANS SHOWING THE MOLECULAR-SIZE DISTRIBUTIONS OF A PETROLEUM FEEDSTOCK AND A PITCH DERIVED FROM THAT FEEDSTOCK.

study. Molecular-size increases with increasing fraction number; thus, the molecular distribution data are expressed in terms of percent composition for four fractions, and may be compared on this basis in Table 1. A preponderance of lower-molecular-size constituents is indicated for the feedstock sample, and the distribution shifts to higher-molecular-size fractions for pitch materials. Distributions of A-170 and A-240 pitches were quite similar, while the distribution of the low-sulfur A-240 would appear to be shifted somewhat toward the lower-molecular-size fractions.

Elemental Compositions - As would be expected from previous discussions, hydrogen-tocarbon $(\mathrm{H} / \mathrm{C})$ atom ratios were in the order: feedstock $>A-170$ pitch $>A-240$ pitch and correspond to values of $1.20,0.78$, and 0.69 , respectively. $A$ value of 0.75 was calculated for the low-sulfur A-240 pitch.

Oxygen content for the A-170 pitch was considerably greater than that of typical A-240 pitch samples, and suggests that oxygen-containing species may become concentrated in the lower temperature fraction. A second observation involves the lower oxygen content for 
low-sulfur A-240 pitch than that measured for A-240 stock samples. Apparently, desulfurization also results in a decrease in oxygen content.

Values for the sulfur contents in Table 1 indicate that no appreciable concentration of sulfur occurs on converting feedstock to pitch. Values typical of feedstock samples were quite similar to the 'value measured for A-170 pitch and were only slightly lower than those typical of A-240 samples. Desulfurization of A-240 pitch reduces the sulfur content by a factor of approximately 10 , with values of 0.1 percent being typical for the process employed.

Ash contents of all the product types were low. Values for feedstocks were approximately 0.1 percent, while those for the A-240 pitches ranged between 0.1 and 0.2 percent. Thus, no significant concentration of inorganic impurities occurs during pitch production, which is not surprising when the method of pitch recovery is considered. Spectrographic analysis of the A-240 pitch sample provided a quantitative estimate of the constituent elements. These data are listed in Table 2 and indicate that aluminum and silicon are the major inorganic contaminants which, in all probability, are introduced as components of the catalysts during the cracking operations. Again, as in the case of the oxygen contents, desulfurization appeared to purge the pitch of most of the metallic constituents, and ash contents decreased by a factor approaching 10 .

Thermal Properties. - Only the A-240 pitch of the materials listed in Table 1 was subjected to thermal analysis. The results, which may be considered typical of all A-240 pitch samples, are summarized in Figure 3. Fusion of the pitch occurs over a range of temperatures and thus did not result in a measurable thermal response. The thermal response did, however, undergo a slow endothermic drift. with increasing temperature. This trend became more pronounced at temperatures above $250^{\circ} \mathrm{C}$ and was climaxed by an abrupt exotherm occurring at approximately $540^{\circ} \mathrm{C}$. The endothermic response corresponds to a loss of volatiles, while the exothermic response denoted pyrolytic polymerization. Thermal gravimetric data show little weight loss below $300^{\circ} \mathrm{C}$ with about 60 percent of the initial sample weight being lost by the time the sample reached $600^{\circ} \mathrm{C}$.

Coke Yields - Coke-yield values for the low-sulfur pitch were slightly higher than those of stock A.240 pitch. This fact is apparent in Table 1 and was supported by more extensive coke-yield studies. Thus, the desulfurization process appears to enharice the reactivity of the pitch toward thermally induced polymerization. The relationship between coke yields of A-170 and A-240 pitches is apparent in Table 1 and correlates with the other property differences.
Table 2

SPECTROGRAPHIC ANALYSIS OF A-240 PITCH

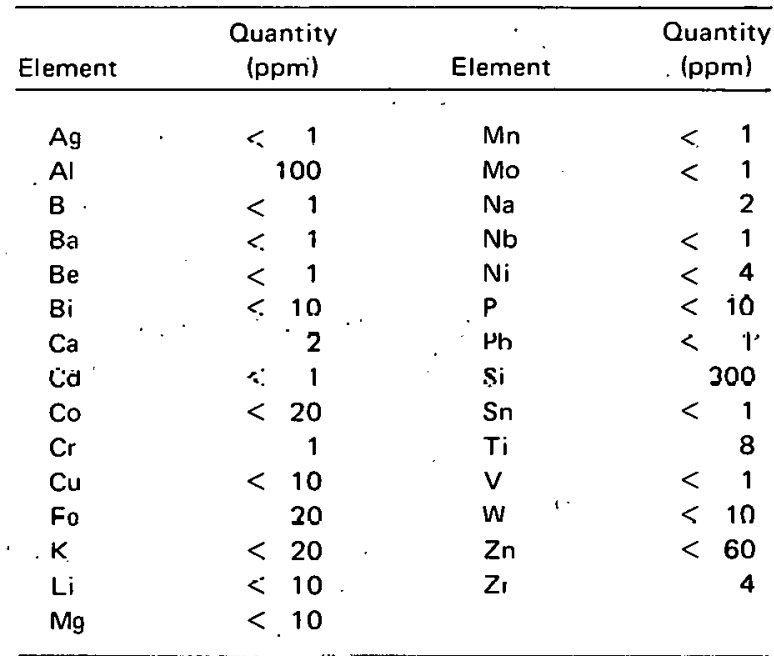


Summary - Many of the properties of the feedstock and A-240 pitch samples listed in Table 1 may not be typical of these two product types, but average properties of these two types give a reasonable basis for evaluating property changes that occur when feedstock is converted to pitch. Removal of sulfur from A-240 pitch also reduced the levels of oxygen and metallic constituents, and appeared to increase the coke-yield values.

\section{Characterization Studies Using Nuclear Magnetic Resonance Techniques}

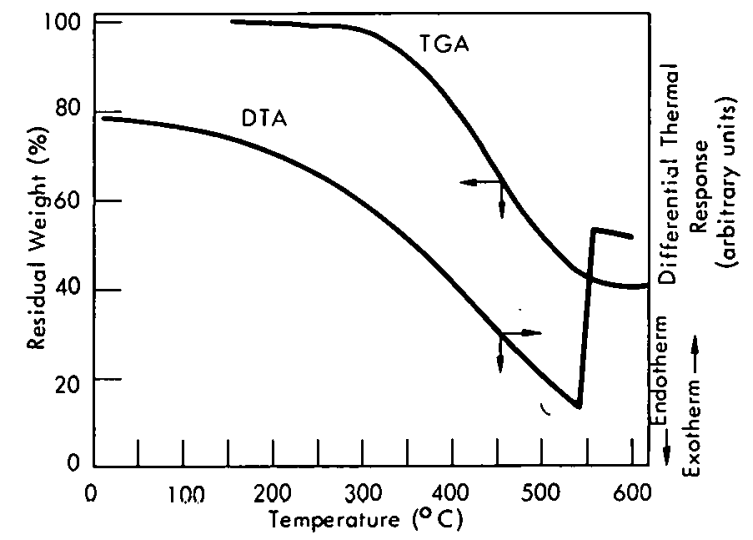

Figure 3. THERMOGRAM OF TYPE A-240 PITCH. (Heating Rate, $6^{\circ} \mathrm{C} / \mathrm{min}$ )

This phase of the study involved the use of NMR data to obtain a more detailed characterization of feedstock and pitch materials. Such an analysis allows an estimation to be made of the composition and structure of the molecular types that compose these materials. This approach follows that described by Williams, ${ }^{(2)}$ and makes use of elemental-composition and molecular-weight data in conjunction with proton distributions that may be obtained from high-resolution NMR spectra. Since the input data that were used represent average properties, the results of the study should be considered as averaged over all molecular species in the sample. Mathematical equations and the major assumptions associated with the method are listed in Appendix $\mathrm{C}$.

Prior to a discussion of results, a look at typical NMR spectra will aid in understanding the source and interpretation of the proton distribution data. Spectra of four petroleum material types are presented in Figure 4. Those proton classifications that were required in this study are given in Part a of Figure 4. Williams (2) divides the protons into three groups: aromatic $\left(H_{A}^{*}\right)$, a-alkyl $\left(H_{a}^{*}\right)$, and other alkyl $\left(H_{\beta}^{*}+H_{\gamma}^{*}\right)$. As noted in Figure 4, the NMR response of protons associated with aromatic carbons is easily distinquished from that of the aliphatic protons. Likewise, the response of $a$-alkyl groups is readily distinguished from that of the aliphatic protons. The a-alkyl response accounts for protons that are on aliphatic carbon atoms which are adjacent to aromatic nuclei. Protons on carbons which are beta or higher to aromatic nuclei yield a variety of NMR signals. This condition is due to a great variety in the structural environments that exist for aliphatic protons in complex structures such as are characterized by petroleum materials. Thus, further classification of proton types is difficult.

Compounds incorporating proton types similar to those found in the petroleum materials are illustrated in Figure 5. Aliphatic proton types include alpha-methylene, beta-methylene, beta-methyl, and gamma-methyl hydrogens. Williams would associate the first with "a-alkyl" groups and the latter three types with the "other alkyl" groups. Thus, this latter classification may be said to include all methyl or methylene groups that are more than one carbon removed from an aromatic ring.

As can be seen in Figure 4, all the petroleum materials have an aromatic proton response at greater than $8 \mathrm{ppm}$, which is characteristic of certain fused-ring systems. One such system (that of phenanthrene) is shown in Figure 5(a), which depicts a specific proton environment that gives rise to this NMR response. The isomeric structure (corresponding 


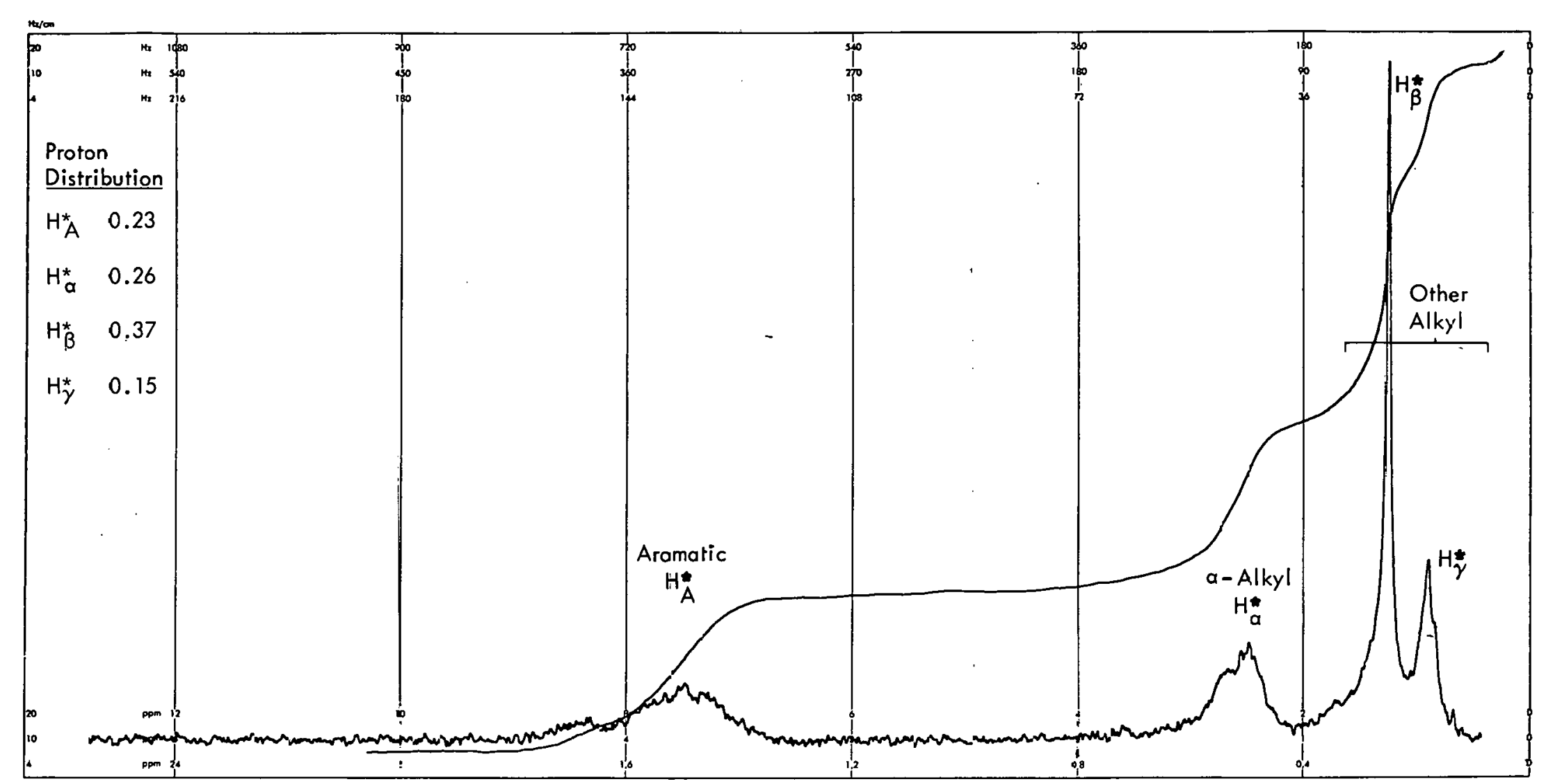

(a) Peircleum Feedstock RD-79P.

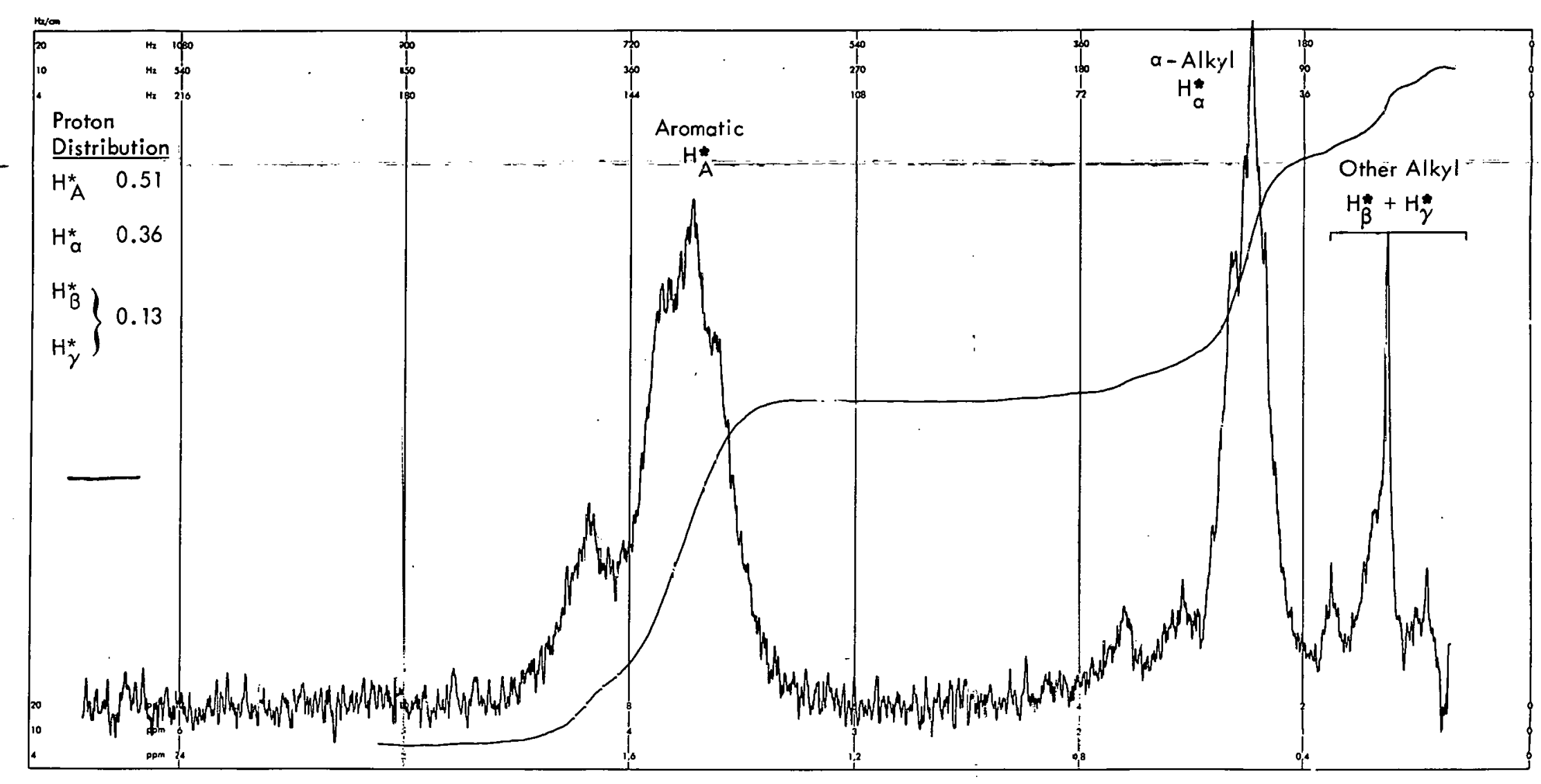

(b) A-170 Petroleum Firch.

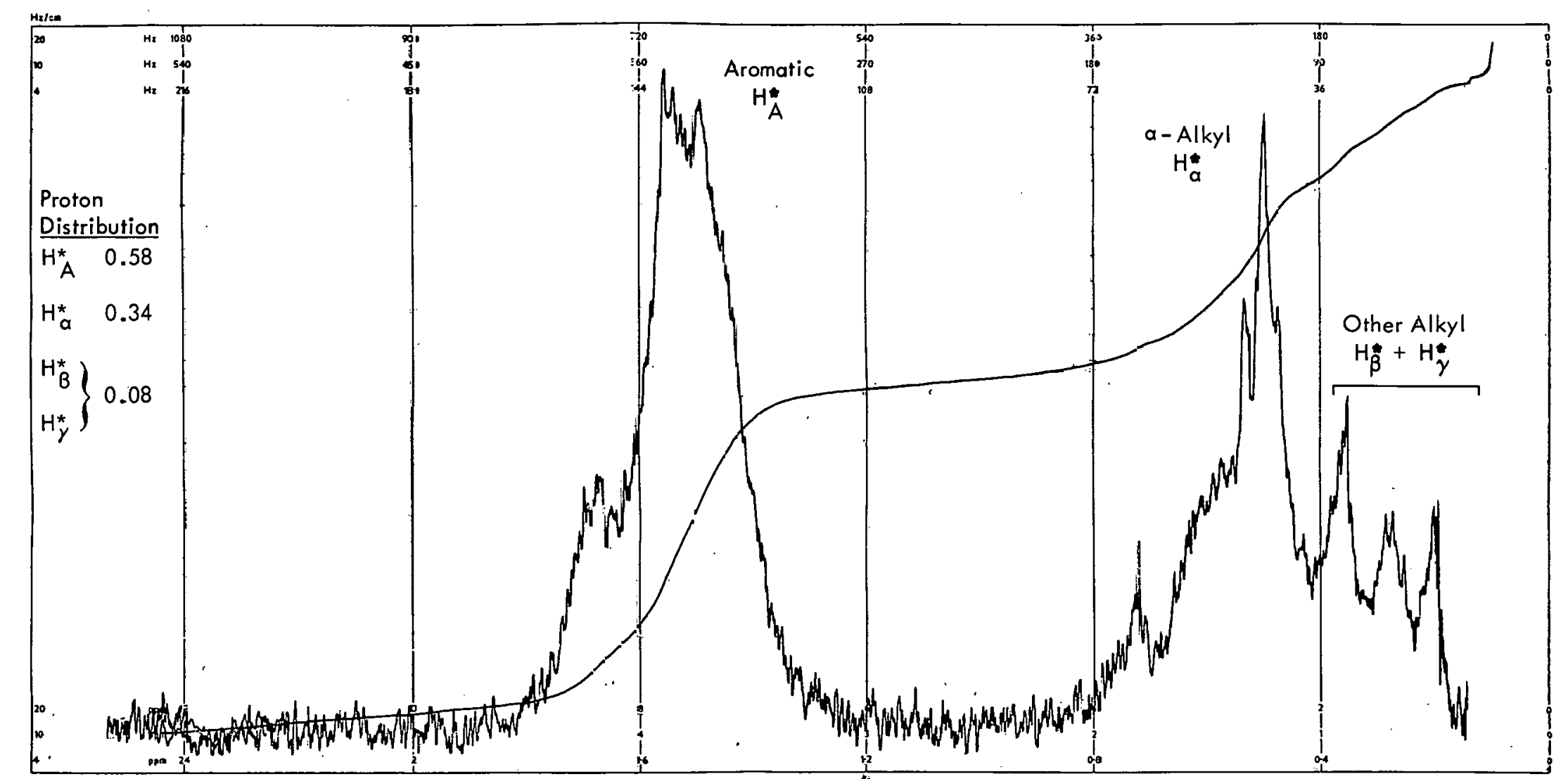

(c) A-240 Petroleum Pitch RD-80P.

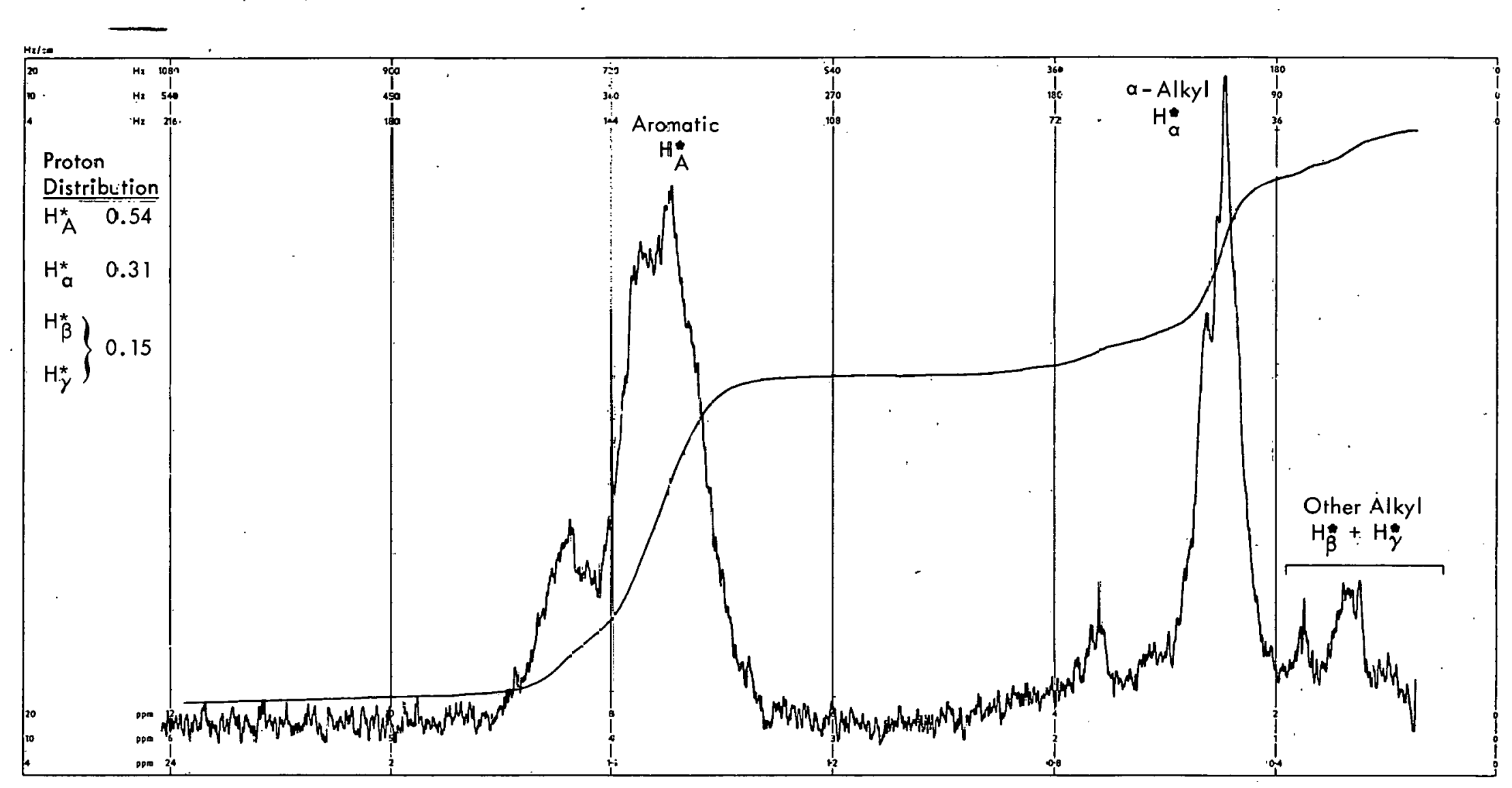

(d) A-240 Petroleum Pitch (low sulfur! RD-72P. 

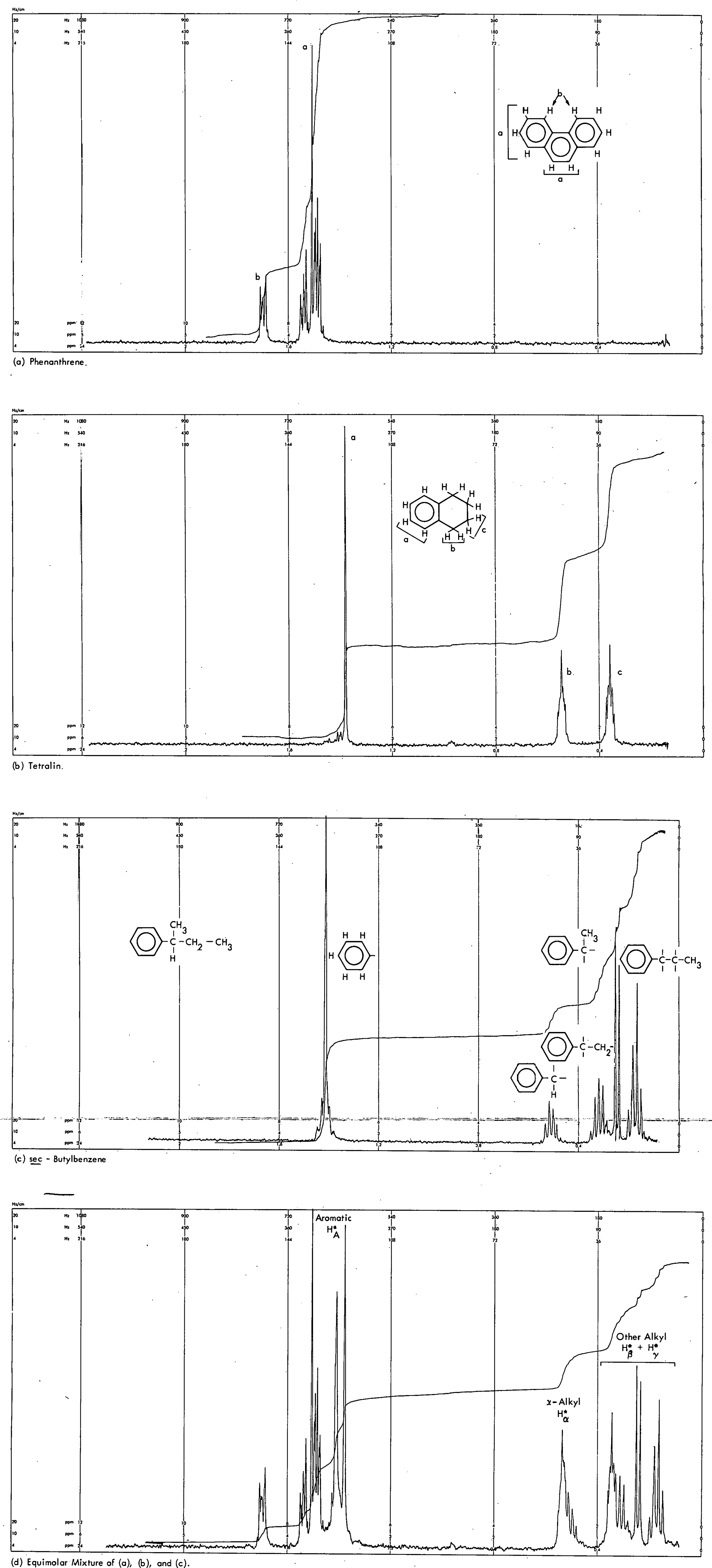
to anthracene) does not yield this specific response. Thus, it can be assumed that ring systems in the petroleum materials incorporate protons that share the same relative positions as are depicted in the formula in Figure 5(a).

Aliphatic groups that are part of a ring structure are given in Figure 5(b). According to the method of Williams, the four-carbon aliphatic group in tetraline $(1,2,3$, 4-tetrahydronaphthalene) would consist of two substituent groups of two carbons each, and four of the protons would be classified as "a-alkyl" and four as "other alkyl". The spectrum of sec-butylbenzene in Figure 5(c) incorporates many of the structure types that would be found in acyclic aliphatic substituents on aromatic rings. A combination of the three compounds in Figure 5(d) gives a spectrum that begins to look similar in complexity to those obtained for the petroleum pitch products shown in Figure 4, charts (b), (c), and (d).

Calculations associated wilh this NMR method do not require the separate classification of $H_{\beta}^{*}$ and $H_{\gamma}^{*}$ protons, but do require a peak-height ratio of $H_{j}^{*}$ and $H_{\beta}^{*}$. These data are easily calculatcd tor tccdstock materials, but are less accurate for pitch spectra due to reduced resolution. Therefore, no detailed calculations were carried out for A-240 pitch samples. However, a complctc analysis of A-170 pitch was attempted, and is disisusied in the following paragraphs along with data obtained for other petroleum product types.

Petroleum Feedstocks - The high degree of spectral resolution of feedstock samples made these materials amenable to detailed characterization using NMR techniques. Feedstocks showed good resolution between the two bands that were collectively classified as "other alkyl". One proton type $\left(H_{\beta}^{*}\right)$ corresponds to methylene hydrogen while the second $\left(H_{\gamma}^{*}\right)$ corresponds to termial methyl groups. There would, of course, be some exceptions to such a simple classification. For example, methyl groups that are beta-to-aromatic nuclei would probably be measured as $\mathrm{H}_{\beta}^{*}$ proton types.

Four of the feedstock samples were analyzed in detail and are presented in Table 3 along with NMR data for all the feedstock. samples. (Elemental compositions and molecular weight data that were used in the calculations are presented latcr Tablc 12.)

Proton Distributions - Proton distributions are expressed as normalized integrated intensities that were measured from NMR spectra for the proton types that are presented in Figure 4. As is evident in Table 3, there was considerable variability in

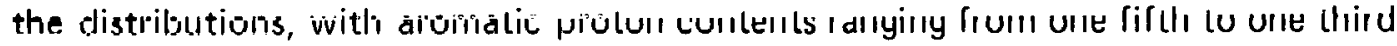
of the tulal protun content. Somewhat similar varlabllities existed for the aliphatic proton types. Individual estimates were made for the protnn types $\left(\mathrm{H}_{\beta}^{*}\right.$ and $\left.\mathrm{H}_{,}^{*}\right)$ that were classified as "other alkyl".

In general, the aliphatic proton distributions suggest: (1) comparatively short aliphatic chains (high values for $\mathrm{H}_{a}^{*}$ relative to values for $\left.\mathrm{H}_{\beta}^{*}+\mathrm{H}_{\gamma}^{*}\right) ;(2)$ a low degree of chain branching (relatively small values for $\mathrm{H}_{\gamma}^{*}$ ), and (3) cyclic structures (high values of $H_{a}^{*}$ and $H_{\beta}^{*}$ relative to $H_{\gamma}^{*}$ ).

Proton distribution data form the hassis for calculating the other properties discussed in the subsections to follow. 
Table 3

ANALYSIS OF PETROLEUM FEEDSTOCKS BY NUCLEAR MAGNETIC RESONANCE TECHNIQUES

\begin{tabular}{|c|c|c|c|c|c|c|c|c|c|c|c|c|c|c|}
\hline \multirow[b]{2}{*}{ Notation } & \multirow[b]{2}{*}{ Property } & \multicolumn{9}{|c|}{ Sample and Month } & \multirow[b]{2}{*}{ Mean } & \multirow[b]{2}{*}{$\begin{array}{r}\text { Standard } \\
\text { Deviation }\end{array}$} & \multicolumn{2}{|c|}{ Coefficient of } \\
\hline & & $\begin{array}{l}\text { RD-59P } \\
\text { January }\end{array}$ & $\begin{array}{l}\text { RD-65P } \\
\text { February }\end{array}$ & $\begin{array}{l}\text { RD.74P } \\
\text { March }\end{array}$ & $\begin{array}{l}\text { RD-79P } \\
\text { April }\end{array}$ & $\begin{array}{l}\text { RD-89P } \\
\text { May }\end{array}$ & $\begin{array}{l}\text { RD-91P } \\
\text { June }(1)\end{array}$ & $\begin{array}{l}\text { RD-93P } \\
\text { June }\end{array}$ & $\begin{array}{c}\text { RD-99P } \\
\text { July }\end{array}$ & $\begin{array}{l}\text { RD.130P } \\
\text { January }\end{array}$ & & & $\begin{array}{c}\text { Variation } \\
(\%)\end{array}$ & \\
\hline$H_{A}^{*}$ & $\begin{array}{l}\text { Proton Distribution } \\
\text { Aromatic }\end{array}$ & 0.23 & 0.26 & 0.20 & 0.23 & 0.27 & 0.32 & 0.30 & 0.26 & 0.31 & 0.26 & 0.04 & 15.4 & \\
\hline$H_{a}^{*}$ & $\begin{array}{r}\text { Aliphatic } \\
a-\text { Alkyl }\end{array}$ & 0.24 & 0.27 & 0.25 & 0.26 & 0.25 & 0.28 & 0.27 & 0.29 & 0.26 & 0.26 & 0.02 & 7.7 & \\
\hline $\mathrm{H}_{\beta}^{*}$ & & 0.39 & 0.35 & 0.40 & 0.37 & 0.35 & 0.29 & 0.31 & 0.32 & 0.30 & 0.34 & 0.04 & 11.8 & \\
\hline$H_{\gamma}^{*}$ & Other Alkyl & 0.15 & 0.12 & 0.15 & 0.15 & 0.14 & 0.11 & 0.12 & 0.13 & 0.13 & 0.13 & 0.02 & 15.4 & \\
\hline$c_{s}$ & Saturated Carbon Content (\%) & 35.6 & & & 36.6 & & & 29.3 & & 30.6 & 33.0 & 3.6 & 10.9 & \\
\hline $\mathrm{f}$ & $\begin{array}{l}\text { Carbon/Hydrogen Weight } \\
\text { Ratio of Alkyl Groups }\end{array}$ & 5.35 & 5.22 & 5.35 & 5.29 & 5.30 & 5.09 & 5.14 & 5.15 & 5.18 & 5.23 & 0.10 & 1.9 & $i$ \\
\hline$x$ & $\begin{array}{l}\text { Hydrogen/Carbon Atom Ratio } \\
\text { of Alkyl Groups }\left(\mathrm{CH}_{X}\right)\end{array}$ & 2.24 & 2.30 & 2.24 & 2.27 & 2.26 & 2.36 & 2.33 & 2.33 & 2.32 & 2.29 & 0.04 & 1.7 & 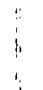 \\
\hline$n$ & $\begin{array}{l}\text { Number of Carbon Atoms } \\
\text { per Alkyl Group }\end{array}$ & 3.2 & 2.7 & 3.2 & 3.0 & 3.0 & 2.4 & 2.5 & 2.6 & 2.7 & 2.8 & 0.3 & 10.7 & . \\
\hline$n x$ & $\begin{array}{l}\text { Number of Hydrogen Atoms } \\
\text { per Alkyl Group }\end{array}$ & 7.0 & 6.2 & 7.0 & 6.9 & 6.9 & 5.8 & 5.8 & 6.0 & 6.3 & 6.4 & 0.5 & 7.8 & . \\
\hline $\mathrm{RS}_{\mathbf{S}}$ & $\begin{array}{l}\text { Number of Alkyl } \\
\text { Substituents per Molecule }\end{array}$ & 2.8 & & & 3.1 & & & 2.6 & & 3.5 & 3.0 & 0.4 & 13.3 & . \\
\hline$c_{A}$ & Aromatic Carbon Content (\%) & 54.1 & & & 53.2 & & & 60.2 & & 60.0 & 56.9 & 3.7 & 6.5 & : \\
\hline$f_{a}$ & $\begin{array}{l}\text { Molar Ratio of Aromatic } \\
\text { Carbon to Total Carbon }\end{array}$ & 0.60 & & & 0.59 & • & & 0.67 & & 0.60 & 0.63 & 0.01 & 6.3 & 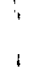 \\
\hline$R_{A}$ & $\begin{array}{l}\text { Number of Aromatic Rings } \\
\text { per Molecule }\end{array}$ & 3.4 & & & 3.0 & & & 3.2 & & 2.9 & 3.1 & 0.2 & 6.5 & 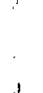 \\
\hline${ }^{*} \mathrm{C}_{\mathrm{A}}$ & $\begin{array}{l}\text { Number of Aromatic-Fing } \\
\text { Carbon Atoms per Molecule }\end{array}$ & 13.5 & & & 13.3 & & & 13.7 & & 13.8 & 13.6 & 0.2 & 1.5 & 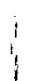 \\
\hline$c_{1}$ & $\begin{array}{l}\text { Nonbridge Aromatic } \\
\text { Carbon Content (\%) }\end{array}$ & 34.9 & & & 37.2 & & & 40.6 & & 43.4 & 39.0 & 3.7 & 9.5 & 1 \\
\hline${ }^{*} c_{1}$ & $\begin{array}{l}\text { Number of Nonbridge } \\
\text { Aromatic-Ring Carbon Atoms } \\
\text { per Multcule }\end{array}$ & 8.7 & & & 9.3 & & & 9.2 & & 10.0 & 9.3 & 0.5 & 5.4 & 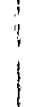 \\
\hline AS & $\begin{array}{l}\text { Fraction of the Nonbridge } \\
\text { Aromatic-Ring Carbon Atoms w }\end{array}$ & & & & & & & & & & & & & $\vdots$ \\
\hline & Alkyl Substituents (\%) & 31.8 & & & 33.2 & & & 27.8 & & 35.2 & 32.0 & 9.8 & 30.6 & 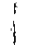 \\
\hline$R_{N}$ & $\begin{array}{l}\text { Number of Naphthenic } \\
\text { Rings per Molecule }\end{array}$ & 0.31 & 8 & & 0.30 & & & 0.19 & & 0.29 & 0.27 & 0.06 & 22.2 & 1 \\
\hline $\mathrm{r}$ & $\begin{array}{l}\text { Number of Naphthene } \\
\text { Riilys per Substitucnt }\end{array}$ & 0.11 & 0.10 & 0.11 & 0.10 & 0.11 & 0.07 & 0.07 & 0.08 & 0.08 & 0.09 & 0.02 & 22.2 & 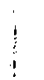 \\
\hline
\end{tabular}

(1) Two samples were processed in June.

(2) Standard deviation/mean $\times 100$. 
Carbon Distributions - Distributions of carbon between the aliphatic and aromatic moieties were calculated for four feedstock samples. As listed in Table 3, the saturated carbon content $\left(C_{S}\right)$ ranged from 29 to 37 percent and the aromatic carbon content $\left(C_{A}\right)$ ranged from 53 to 60 percent. These data again suggest sample-to-sample variability in the molecular composition of feedstock materials; however, the total carbon contents $\left(C_{S}+C_{A}\right)$ of the four samples were quite similar, ranging from 89.5 to 90.6 percent. Carbon distributions between aromatic and aliphatic moieties can be described in terms of their aromaticity values $\left(f_{a}\right)$ which correspond to molar ratios of aromatic to total carbon: $\left(C_{A} / C_{A}+C_{S}\right)$. Values for $f_{a}$, as listed in Table 3, ranged from 0.59 to 0.67 for the four feedstock samples studied.

Distribution of aromatic carbon between bridye and nonbridge ring positions was also calculated. A differentiation of these carbon typos is shown in the followirig structural formula:

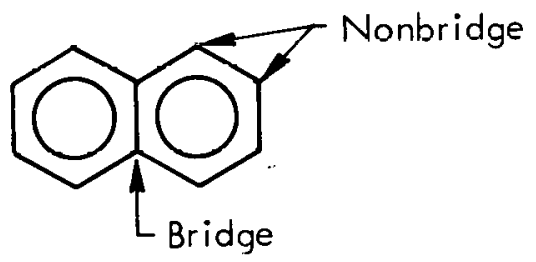

Thus, the nonbridge aromatic carbon content $\left(C_{1}\right)$ of the four samples ranged between 35 and 43 persent, and represented 65 to 72 percent of the total aruinalic carbon content.

Characterization of the Alkyl Substitucnts - Using the equations in Appendix $C$, molecular compositions of alkyl substituents were calculated for all feedstock samples, and are listed in Table 3. Carbon-to-hydrogen weight ratios ( $f$ ) ranged from 5.09 to 5.35, giving rise to empirical formulas ranging from $\mathrm{CH}_{2.36}$ to $\mathrm{CH}_{2.24}$. Further clarification of the nature of the alkyl groups was obtained by calculating the rimber of carbon atoms per alkyl substituent $(n)$ which ranged from 2.4 to 3.2 for the feedstock eamples studicd. These values, in cunjunction with the empirical formulas, permit the calculation of the molecular formulas for alkyl suhstituents. Hydrogen-to-carbon atom ratios for these groups were, in general, lower than would be calculated for acyclic alkyl groups of chain lengths corresponding to the listed values of $n$. Thus, the presence of some substituents with lower $H / C$ ratios is indlcated, and suggests sume content of alicyclic rings which have maximum $\mathrm{H} / \mathrm{C}$ ratios of 2. Real values would be somewhat less and would be dependent on the ring size and degree of substitution of the ring. Though alicyclic (or naphthenic) ring sizes could not be determined, the number of naphthenic rings per molecule $\left(R_{n}\right)$ was calculated for four samples, and the values ranged from 0.19 to 0.31 . Thius, at the lower limit there would be one naphthene ring per five molecules, while the upper limit corresponds to one ring per three molecules.

An additional property calculated from NMR data for three samples was the number of alkyl substituents per molecule $\left(R_{s}\right)$. These values (as listed in Table 3 ) ranged from 2.6 to 3.5 for the three samples studied, and represent both acyclic and 
alicyclic substituents. The numbers of alicyclic rings per substituent $(r)$ are listed in Table 3 for all feedstock samples included in the study.

Characterization of the Aromatic Groups - This characterization was obtained on four feedstock samples, and is included in Table 3. Values for the number of aromatic rings per molecule $\left(R_{A}\right)$ ranged from 2.9 to 3.4 , and the corresponding number of aromatic carbon atoms per molecule $\left(\# C_{A}\right)$ ranged from 13.3 to 13.8. Of the ring atoms, the number that were nonbridge atoms $\left(\# C_{1}\right)$ ranged from 8.7 to 10 . The fraction of nonbridge atoms with alkyl substituents (AS) (as listed in Table 3) should correspond to the ratio of $R_{S} / \# C_{1}$. Values for $A S$ ranged from 27.8 to 35.2 percent for the four feedstock samples.

Structural Analysis of Feedstock RD-79P - A single sample of feedstock was chosen to exemplify construction of a molecular formula from the NMR data presented in Table 3, and to show correlations between the measured properties and those calculated from NMR data. Data from Table 3 for RD-79P indicate an average alkyl group composition of $\mathrm{C}_{3.0} \mathrm{H}_{6.9}$ with 3.1 of these substituent groups in an average molecule. Other data indicate the presence of 13.3 aromatic ring carbon atoms per average molecule. Using the generalized molecular formula listed in Appendix $\mathrm{C}$, the calculated molecular formula is $\mathrm{C}_{13.3} \mathrm{H}_{6.2}\left(\mathrm{C}_{3.0} \mathrm{H}_{6.9}\right)_{3.1}$, which is in good agreement with that determined from molecular-weight and elemental-composition data only. This comparison may be made in Table 4, which also expresses the correlation in terms of molecular weight and elemental composition. The aromatic proton distribution data in Table 4 were included to demonstrate, in part, the validity of the equations used in the calculations in that the value of $\mathrm{H}_{A}^{*}$ obtained from the calculated molecular formula was no different than that obtained directly from NMR spectra and used as input in the calculations.

Table 4

COMPARISON OF THE MEASURED AND CALCULATED PROPERTIES FOR FEEDSTOCK SAMPLE RD-79P

\begin{tabular}{|c|c|c|}
\hline Prupter iy & Measured & Ciàlculàted (1) \\
\hline \multirow[t]{3}{*}{ Molecular Formula } & $\mathrm{C}_{22.5} \mathrm{H}_{27.1}{ }^{(2)}$ & $\mathrm{C}^{{ } \mathrm{C}_{A}}{ }^{\left.H_{\left(\# C_{1}\right.}-R_{s}\right)}\left(C_{n} H_{n x}\right)_{R_{s}}$ \\
\hline & & $\mathrm{C}_{13.3} \mathrm{H}_{6.2}\left(\mathrm{C}_{3.0} \mathrm{H}_{6.9}\right)_{3.1}$ \\
\hline & & $\mathrm{C}_{22.6} \mathrm{H}_{27.6}$ \\
\hline Molecular Weight & 301 & 299 \\
\hline Carbon Content (\%) & 89.8 & $89.6^{(3)}$ \\
\hline Hydrogen Content (\%) & 9.0 & $9.1^{(3)}$ \\
\hline Aromatic Proton Content $\left(H_{A}^{*}\right)$ & $0.23^{(4)}$ & 0.22 \\
\hline
\end{tabular}

(1) Using the technique of Williams (see Reference 2).

(2) Obtained by using elemental-composition and average-molecular-weight data,

(3) Corrected to account for the constituents other than carbon and hydrogen.

(4) From the NMR spectrum. 
In attempting to visualize the possible aromatic structures of an average molecule of RD-79P, models were constructed and were correlated with the observed data. The models, as given in Table 5, represent relatively simple aromatic structures. Thus, the average molecule for Sample RD-79P can be visualized as consisting of three fused aromatic rings with approximately three alkyl substituents, each composed of approximately three carbon atoms.

Table 5 AVERAGE PROP.ERTIES CALCULATED FOR FEEDSTOCK SAMPLE RD-79P

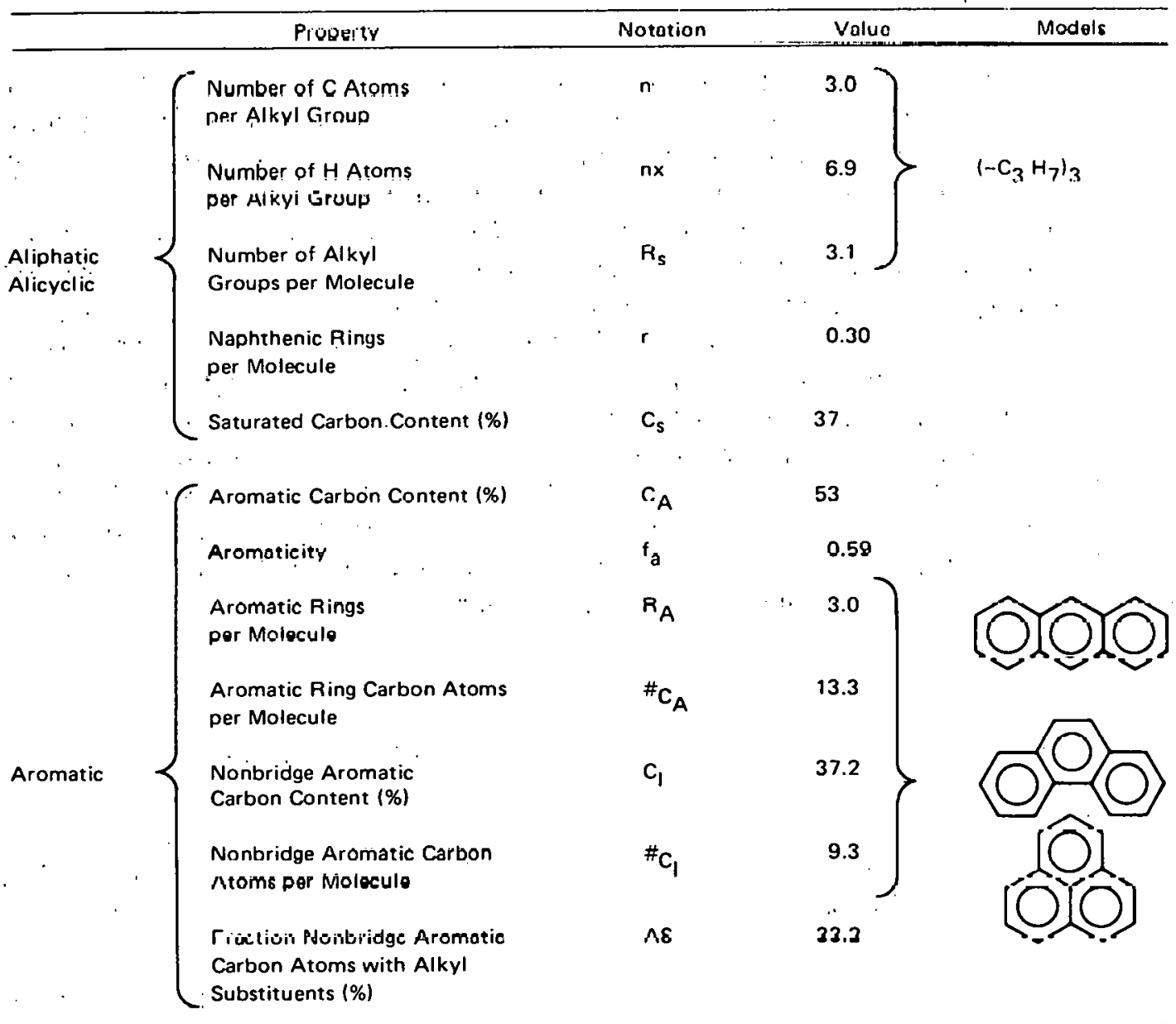

A-170 Pitch - A single sample of A-170 pitch was subjected to NMR analysis similar to that discussed for the feedstock samples. As can be seen in Figure 4(b), the aliphatic proton spectrum is more complex than that observed for feedstocks, and thus data obtained from this analysis would be less accurate than that presented for feedstocks. 'However, an estimate of the average molecular structure should be beneficial in establishing the major differences between molecular compositions of pitch and feedstock. Data obtained for the sample are listed in Table 6.

Proton Distributions - As shown in Figure 4, the aromatic proton contents of the pitches are considerably greater than those of feedstocks. In addition, significant 
Table 6

ANALYSIS OF PETROLEUM PITCH A-170 BY NUCLEAR MAGNETIC RESONANCE TECHNIQUES

\begin{tabular}{|c|c|c|c|c|c|}
\hline c & Carbon Content (\%) & 91.80 & $\mathbf{R}_{s}$ & Number of Alkyl Substituents per Molecule & 3.29 \\
\hline H & Hydrogen Content (\%) & 5.98 . & $c_{A}$ & Aromatic C Content $(\%)$ & 78.82 \\
\hline & Proton Distribution & & $f_{A}$ & Molar Ratio Aromatic to Total C & 0.86 \\
\hline$H_{A}^{*}$ & $\begin{array}{l}\text { Aromatic } \\
\text { Aliphatic }\end{array}$ & 0.51 & $\mathbf{R}_{\mathbf{A}}$ & Number of Aromatic Rings per Molecule & 6.66 \\
\hline$H_{a}^{\prime \prime}$ & a-Alkyl & 0.36 & ${ }^{\#} C_{A}$ & $\begin{array}{l}\text { Number of Aromatic Ring C Atoms per } \\
\text { Molecule }\end{array}$ & 27.26 \\
\hline$H_{\beta}^{*}$ & Other AlkyI & 0.10 & $c_{1}$ & Nonbridge Aromatic C Content (\%) & 46.11 \\
\hline$H_{\gamma}^{*}$ & 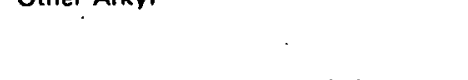 & 0.03 & $\# \mathrm{C}_{1}$ & $\begin{array}{l}\text { Number of Nonbridge Aromatic Ring C } \\
\text { Atoms per Molecule }\end{array}$ & 15.95 \\
\hline $\mathrm{C}_{\mathrm{s}}$ & Saturated Carbon Content (\%) & 13.0 & & & \\
\hline$f$ & C/H Weight Ratio of Alkyl Groups & .4 .42 & AS & $\begin{array}{l}\text { Fraction of Nonbridge Aromatic } \\
\text { Ring C Atoms with Alkyl Substituents (\%) }\end{array}$ & 20.62 \\
\hline$x$ & H/C Atom Ratio of Alkyl Groups & 2.72 & $\mathbf{R}_{\mathbf{n}}$ & Number of Naphthenic Rings per Molecule & 0.06 \\
\hline $\mathbf{n}$ & Number of C Atoms per Alkyl Group & 1.35 & $\mathbf{r}$ & Number of Naphthene Rings per Substituent & 0.02 \\
\hline$n \times$ & Number of $\mathrm{H}$ Atoms per Alkyl Group & 3.68 & & & \\
\hline
\end{tabular}

differences in the aliphatic proton distributions are apparent when feedstock data are compared with that for A-170 pitch in Table 6. Generalized observations from the aliphatic proton distribution are:

1. Aliphatic chains are quite short; much shorter than those observed for feedstocks (based on a high value of $H_{a}^{*}$ ).

2. Considering $H_{\beta}^{*}$ to represent methylene and beta-methyl protons, there are relatively few alkyl groups containing two carbon atoms.

3. Considering $\mathrm{H}_{\gamma}^{*}$ to represent terminal methyl groups in the gamma (or higher) positions, an even smaller number of the alkyl groups consist of three or more carbon atoms.

Carbon Distributions - As expected, pitch samples are much higher in their aromatic carbon content $\left(C_{A}\right)$ than feedstocks. For example, the value of $C_{A}$ for $A-170$ pitch was 78.8 percent; the nonbridge carbon content was 46.1 percent. $A$ value of 13.0 percent was calculated for saturated carbon $\left(C_{s}\right)$. Collectively, these data give an aromaticity value $\left(f_{a}\right)$ of 0.86 .

Characterization of the Alkyl Substituents-The $\mathrm{C} / \mathrm{H}$ weight ratio for alkyl groups in the pitch was 4.42, which results in an empirical formula of $\mathrm{CH}_{2.72}$. The $\mathrm{H} / \mathrm{C}$ atom ratio is higher than that of the feedstocks $(\sim 2.23)$ and suggests a preponderance of methyl groups $(\mathrm{H} / \mathrm{C}=3)$. 
The probability of larger acyclic alkyl groups remaining intact during the cracking/cyclization reactions that accompany production of the pitch is small. Thus, in addition to methyl groups, there would be alicyclic rings which would result in an overall average $\mathrm{H} / \mathrm{C}$ atom ratio somewhat less than three. The number of carbon atoms per alkyl group (n) was 1.35, and the number of alkyl substituents per molecule was approximately 3.3. Collectively, these data suggest an average of 3.3 alkyl groups per molecule, with an average composition of $\mathrm{C}_{1.35} \mathrm{H}_{3.68}$.

Characterization of the Aromatic Groups-Calculations revealed that aromatic groups in pitches were much larger than those discussed for feedstock samples. The value for the number of aromatic rings per molecule $\left(R_{A}\right)$ was 6.66 , while the corresponding number of carbon atoms $\left(\# C_{A}\right)$ was 27.26. Of the total aromatic ring carbon atoms, 15.95 atoms were in nonbridge positions, and 20.6 percent of the nonbridge atoms had alkyl substituents.

Structural Allalysis of A-170 Pitch Collcctivcly, thoso data allow visualization nf a structure representing an average of all molecules in the A-170 pitch sample. The alkyl group composition was $\mathrm{C}_{1.4} \mathrm{H}_{3.7}$, and 3.3 of these groups are present as substituents in an average molecule. Aromatic moieties average 6.7 aromatic rings per molecule and are composed of 27.3 aromatic carbon atoms. Using the generalized molecular formula listed in Appendix $\mathrm{C}$, the calculated molecular formula from these data is $\mathrm{C}_{27.3} \mathrm{H}_{12.7}\left(\mathrm{C}_{1.4} \mathrm{H}_{3.7}\right)_{3.3}$. This and other calculated properties may be compared with the measured properties in Table 7. A comparison of the measured and calculated proton distribution data show identical values for $\mathrm{H}_{\mathrm{A}}^{*}$, and indicate that the equations used in the calculations did not distort the NMR input data.

Table 7

COMPARISON OF THE MEASURED ANU CALLULATEU PROPERTIES FOR PETROLEUM PITCH A-170

\begin{tabular}{|c|c|c|}
\hline Property & Measured & Calculated(1) \\
\hline Molecular rormula & $\mathrm{C}_{32.4} \mathrm{H}_{2 b .4}{ }^{(2)}$ & $C_{31.7} \mathrm{H}_{24.7}$ \\
\hline Molecular Weight & 415 & 405 \\
\hline \multicolumn{3}{|l|}{ Composition (CH only) } \\
\hline Carbon (\%) & 91.80 & $91.82^{(3)}$ \\
\hline Hydrogen. (\%) & 5.98 & $5.96^{(3)}$ \\
\hline Aromatic Proton Distribution $\left(H_{A}^{*}\right)$ & $0.51^{(4)}$ & 0.51 \\
\hline
\end{tabular}

(1) Calculated from NMR data using the technique of Williams. (2)

(2) Obtained from the elemental composition and average molecular weight data.

(3) Corrected to account for constituents other than $\mathrm{C}$ and $\mathrm{H}$.

(4) Measured from NMR spectra.

Models of aromatic structures similar to the average structure determined from NMR data are listed in Table 8 . The models are all based on seven-ring systems, and progress from a linear structure (Model 1) with a high content of peripheral or 
Table 8

SEVEN-RING AROMATIC MODELS CORRESPONDING TO AVERAGE NMR PROPERTIES OF A-170 PETROLEUM PITCH

$\begin{gathered}\text { Model } \\ \text { Number }\end{gathered}$
$\therefore \quad \begin{aligned} & \text { Required for the Seven-Ring System as Per } \\ & \text { NMR Data on A-170 Pitch }\end{aligned}$

Number of Bridge
Carbon Atoms. $\quad \begin{gathered}\text { Number of Nonbridge } \\ \text { Carbon Atoms }\end{gathered}$
- Per Molecule Per Molecule

11.90

16.75

Ratio(1) NMR Data on A-170 Pitch

1<smiles>C1CCC2CC3CC4CC5CC6CCCCC6CC5CC4CC3CC2C1</smiles>

12

18

0.600

2<smiles></smiles>

12

17

0.586

3

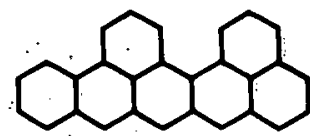

12.

$16^{\circ}$

0.571

-<smiles>C1CCC2CC3C(CC2C1)CC1CCCCC2CC4CCCCC4C4C5CCCCC5CC3C4C12</smiles>

12

17

0.586

4

5<smiles>C1CCC2C(C1)CC1CC3CC4CCCCC4C3CCC3CCC2CC31</smiles>

6

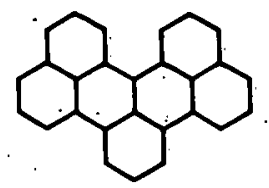

7<smiles>C1CCC2C(C1)CC1C3CCCC4CCCC(C5C6CCCCC6CC25)C4C31</smiles>

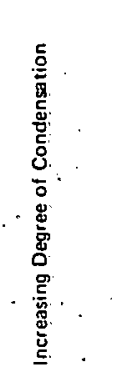

12.

15

0.556

12<smiles></smiles>

12

0.538

9<smiles></smiles>

10

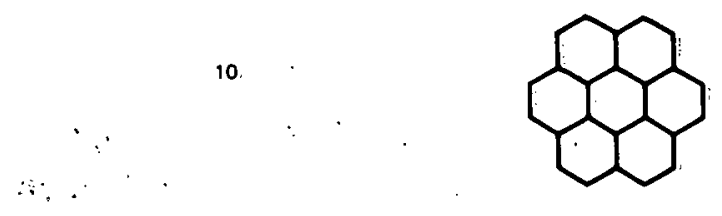

12

12

0.500

(11) Calculatedsas ratio: Number of Nonbridge Carbon. Atoms/Number of Nonbridge Carbon Atoms + Number of Bridge Carbon-Atoms: Values assume no substitution. 
nonbridge carbon atoms to a symmetrical structure (Model 10) having a high degree of condensation and a low content of nonbridge carbon atoms. Table 8 does not include all the structural isomers for the seven-ring systems, but does represent the degrees of ring condensation that are possible. Included in Table 8 are $\mathrm{H} / \mathrm{C}$ atom ratios for the model structures, allowing a comparison with the value obtained by NMR calculations. Though NMR data indicate that 3.45 hydrogen atoms in a seven-ring molecule are substituted by alkyl groups; for the sake of simplicity, values of $\mathrm{H} / \mathrm{C}$ atom ratios in Table 8 assume no substitution. This assumption does not invalidate the comparisons that were made.

Hydrogen-to-carbon atom ratios in aromatic systems containing as many as seven rings are almost independent of the number of aromatic rings per molecule, and the effect decreases with an increasing number of rings. For example, in going from one ring to two rings, the $\mathrm{H} / \mathrm{C}$ atom ratio changes from 1 to 0.8 , or decreases by 20 percent. In going from a linear arrangement of seven rings to a linear arrangement of eight rings, the $\mathrm{H} / \mathrm{C}$ atom ratio decreases by only 0.2 percent. However, as can be seen in Table 8, the $\mathrm{H} / \mathrm{C}$ atom ratios of aromatic ring systems can be significantly influenced by the degree of ring condensation; and, for a seven-ring system, can undergo a decrease of 16.7 percent in changing from linear (Model 1) to its most highly condensed structure (Model 10). Though the molecular distribution in the pitch will include systems containing more and. less than seven rings, it seems reasonable to ignore this lesser effect on the $\mathrm{H} / \mathrm{C}$ atom ratios; and, rather, associate with the atom ratio values the degree of condensation. Of the structures shown in Table 8, Model 1 would be highly improbable, as would Model 10 and perhaps Model 9. Statistical distributions would not tend to include many molecules with such high degrees of order. Thus, if $\mathrm{H} / \mathrm{C}$ atom ratios of other models are compared with that calculated from NMR data, two of the isomeric structures (Models 2 and 4) having the next highest $\mathrm{H} / \mathrm{C}$ atom ratios (0.586) almost exactly duplicate that calculated $(0.585)$, and contributions of other structures having lower $\mathrm{H} / \mathrm{C}$ atom ratio values would seem to be quite small.

In summary, these models are not presented in order to prove or suggest specific molecular structures, but only to indicate the degree of condensation that is most probable for molecules that compose the pitch. Hydrogen-to-carbon atom ratios from the aromatic portion of the calculated molecular formulae of A-170 pitch and feedstock sample RD-79P were identical. The lower $\mathrm{H} / \mathrm{C}$ atom ratio that would be expected for the pitch (due to larger molecules and a higher degree of condensation) is offset by differences in the fraction of hydrogen atoms that are substituted by alkyl groups. This value is 33.2 percent for the feedstock sample and orily 20.6 percent for the pitch sample, indicating that some of the alkyl groups in the feedstock end up through cyclization as components of ring structures in the pitch.

\section{A-240 Pitch -}

Fractionation Studies - As stated previously, NMR spectra of A-240 pitches did not allow a detailed analysis similar to that discussed for feedstocks and A-170 pitch. NMR responses corresponding to aliphatic protons classified as "other alkyl" $\left\langle H_{\beta}\right.$ and $H_{\gamma}$ ) were quite small. In fact, the signal corresponding to the terminal methyl group $\left\langle\mathrm{H}_{\gamma}\right)$ was almost nonexistent. Collectively, $\mathrm{H}_{\beta}$ and $\mathrm{H}_{\gamma}$-type protons 
accounted for only eight percent of the total proton content and 19 percent of the aliphatic proton content. These data are shown with the spectra for A-240 pitch in Figure $4(\mathrm{c})$ and suggest small alkyl substituent groups. As previously listed in Table 1 , a value of $1: 22$ was calculated for: the average number of carbon atoms per alkyl groups in this sample.

A sample of A-240 pitch (RD-90P) was fractionated into five portions using column chromatography techniques, and each fraction was subsequently analyzed for molecular weight and NMR data. The fractionation procedure consisted of placing a sample of the pitch on an alumina column and successively eluting the sample with solvent blends of tetrahydrofuran (THF) and ethanol. Of the two, THF was the superior solvent for A-240 pitch; and, thus, use of the solvent blends was in the order of increasing THF content. Fractions corresponding to each solvent blend were collected, and samples were recovered by evaporation of the eluting solvent. Molecular distributions of four of the fractions may be compared in Figure 6; other data are listed in Table 9. Fractions eluted with solvents containing 0,25 , and 50 percent THF were quite similar in properties and did not differ greatly from the stock A-240 sample. Collectively, these fractions (A, B, and C) account for 73 percent: of the total weight recovered, and could be classified as relatively low molecular. weight materials having nearly identical proton distributions and incorporating small alkyl substituent:groups. Fractions eluted with THF-rich solvent blends exhibited :properties significantly different from the initial three fractions, as reflected in the melting and molecular weight data. Though relatively small in proportion to other fractions, Fraction $E$ has a higher content of aliphatic groups than do the other fractions that were analyzed by NMR. This fact is reflected in a lower value of $H_{A}^{*}$ and a higher value of $\dot{H}_{\beta}^{*}+H_{\gamma}^{*}$. Likewise, size of the alkyl substituents is significantly greater than those calculated for other fractions. Fraction $E$, which did not fuse below $270^{\circ} \mathrm{C}$, probably represents the properties of THF insolubles that remained on the column, though the latter were not charàcterized.

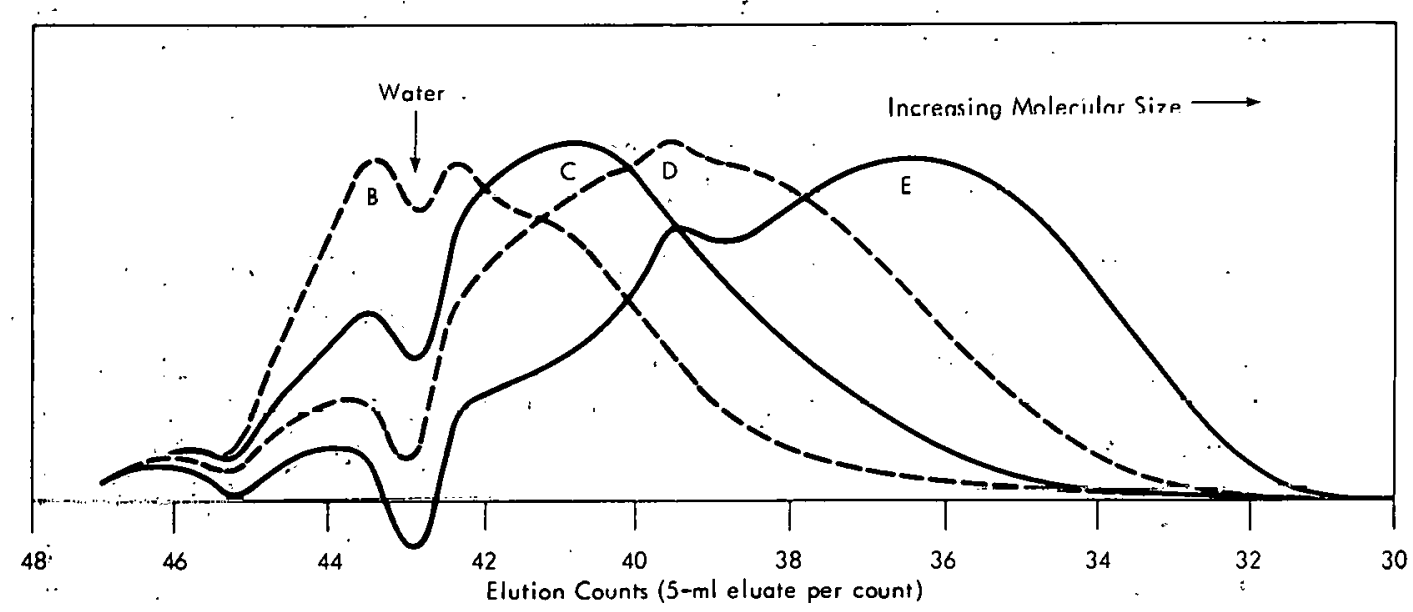

Figure 6: PERMEATION CHROMATOGRAPHIC SCANS SHOWING THE MOLECULAR DISTRIBUTIONS OF'FRACTIONS OF TYPE A.240 PITCH THAT WERE SEPARATED BY COLUMN CHROMATOGRAPHY. 
Table 9

PROPERTIES OF TYPE A-240 PITCH FRACTIONS

\begin{tabular}{|c|c|c|c|c|c|c|c|c|}
\hline Fraction & $\begin{array}{l}\text { Composition } \\
\text { of the Eluting } \\
\text { Solvent }\end{array}$ & $\begin{array}{l}\text { Fraction } \\
\text { Weight (1) }\end{array}$ & $\begin{array}{l}\text { Melting } \\
\text { Range (2) }\end{array}$ & $\begin{array}{l}\text { Average } \\
\text { Molecular }\end{array}$ & \multicolumn{4}{|c|}{ NMR Properties (3) } \\
\hline Number. & (vol $\%$ THF in $\mathrm{C}_{2} \mathrm{H}_{5} \mathrm{OH}$ ) & $(\%)$ & $10 \mathrm{Cl}$ & Weight & $H_{A}^{*}$ & $H_{a}^{*}$ & $\mathrm{H}_{\beta}^{*}+\mathrm{H}_{\gamma}^{*}$ & n \\
\hline $456 \mathrm{~A}$ & - & - & - & 483 & 0.58 & 0.34 & 0.08 & 1.23 \\
\hline $\begin{array}{l}\text { (A-240 Sample } \\
\text { RD-90P) (4) }\end{array}$ & & & & & & & & \\
\hline $4 S 6 A$ & 0 & 13 & $30 \cdot 50$ & 321 & 0.58 & 0.35 & 0.07 & 1.20 \\
\hline $4 \$ 6 \mathrm{~B}$ & 25 & 19 & $50-70$ & 349 & & - & & \\
\hline $4 C 6 C$ & 60 & $\Delta 1$ & $\because 6 \mathbf{U}-\dot{90}$ & 465 & 0.58 & 0.30 & 0.06 & 1.17 \\
\hline $486 \mathrm{D}$ & 75 & 22 & $190-220$ & 709 & & & & \\
\hline & & & 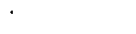 & & $\cdot$ & & & \\
\hline 4S6E & 100 & 5 & $>270$ & 962 & 0.48 & 0.30 & 0.22 & 1.73 \\
\hline
\end{tabular}

(1) Relative to the total sample recovered.

(2) By visual observation on a Fisher-Johns melting point block.

(3) See Appendix $C$ tor definition of symbols.

(4) This sample was placed on an alumina column and successively eluted with solvent blends. Fractions of the eluate were evaporated to dryness and heated under vacuum $(20 \mu \mathrm{m})$ at $90^{\circ} \mathrm{C}$ for 20 hours prior to evaluation.

Low-Sulfur Form - Examination of the NMR spectrum, Figure 4(d), of the low-sulfur form of A-240 pitch reveals a more complex distribution of aliphatic. protons than that observed for stock A-240 or A-170 pitchies. As previuusly noted in Table 1, desulfurization is accompanied by an increase in the alkyl substituent size by 25 percent. These changes in molecular composition due to desulfurization are also reflected in the proton distributions of the low-sulfur form relative to stock A-240 pitch. This comparison may be made in Figure 4. Desulfurization results in slight decreases in aromatic $\left(\mathrm{H}_{A}^{*}\right)$ and $a$-alkyl $\left(\mathrm{H}_{a}^{*}\right)$ protons, and a corresponding increase in "other alkyl" $\left(\mathrm{H}_{\beta}^{*}+\mathrm{H}_{\gamma}^{*}\right)$ protons. Thus, there are possible disruptions of aromatic nuclei, a decrease in a-alkyl groups due to scission from the aromatic ring structures, and a corresponding increase in alkyl chain lengths indicated by increases in methylene and methyl protons on beta (or higher) carbons.

Scission of heterocyclic rings containing sulfur and oxygen cannot account for all of the changes that aocompany desulfurization. This fact is demonstrater hy looking at heterocyclic structural types which would, on scission, produce alkyl chain lengths of two and three carbon atoms. Since the NMR calculation of alkyl substituent size is expressed as the number of carbons atoms per substituent, those substituents that are part of alicyclic ring structures would be considered as one half the size of the rings. Therefore, scission of one end of an alicyclic ring from an aromatic structure would reduce the number of substituents per molecule and effectively increase the calculated values for the alkyl substituent size.

Table 10 provides estimates of the increases in alkyl substituent sizes that would result from assumed heterocyclic structures. This exercise is not designed to prove or suggest the structural forms that may contain sulfur, but does include those 
Table 10

ESTIMATES OF INCREASES IN THE ALKYL SUBSTITUENT SIZES DUE TO DESULFURIZATION OF A-24O PITCH

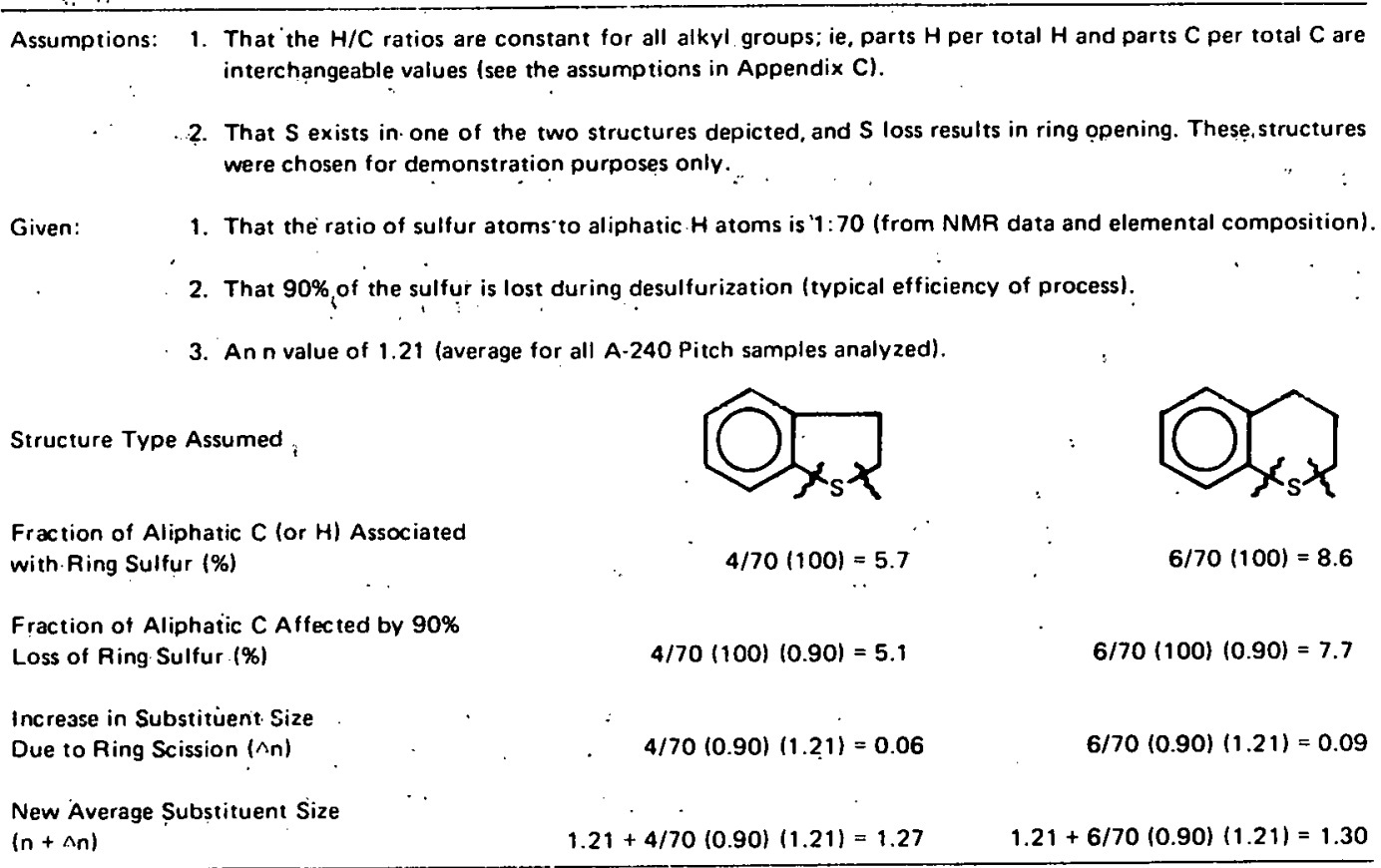

structural types that are likely to produce maximum increases in the alkyl chain length. Larger heterocyclic rings are unlikely, and sulfur in ring positions other than alpha would result in less than maximum increases in the substituent size. Data in Table 10 suggest increases in alkyl substituent sizes of 5.1 and 7.7 percent on desulfurization of five and six-member heterocyclic rings, respectively. As stated previously, an increase of 25 percent was calculated on desulfurization of A-240 pitch. Loss of oxygen could be accompanied by a ring opening, but the maximum effect would be one sixth that calculated for sulfur using the approach outlined in Table 10. Thus, it is probable that additional increases in alkyl substituent sizes must be attributed to the scission of naphthenic or alicyclic structures, with the possible distuption or reduction of some aromatic structures.

Summary - This NMR study of petroleum materials provides the following information:

1. Converting petroleum feedstock to A-170 pitch increases the size of the aromatic groups by greater than a factor of two and decreases the size of the alkyl substituents by more than one half. The number of substituents per molecule $(\sim 3)$ remained essentially the same.

2. Higher-molecular-weight fractions of A-240 pitch are richer in aliphatic carbon than is represented by the average properties of the pitch. Also, this increase is reflected in an increased size per alkyl substituent rather than an increase in the number of substituents per molecule.

3. Desulfurization of A-240 pitch results in ring-opening reactions that include heterocyclic, naphthenic, and possibly aromatic structures. 


\section{Reproducibility Studies}

This phase of the study was designed to evaluate the month-to-month reproducibility of A-240 petroleum pitch and the petroleum feedstocks from which the pitch was made. Thirteen pitch/feedstock sample pairs were received during a one-year sampling program, and analytical data were obtained on ten pitch samples and nine feedstock samples. For the most part, both pitch and feedstock samples were analyzed in random order, with no effort made to analyze the pitch/feedstock sample pairs together. In addition to determining pitch reproducibility, the study was designed to evaluate the relationships that might exist between pitch properties and: (1) feedstock properties, (2) seasonal changes, and (3) equipment or process chanyes.

With respect to the latter, signiticant renovation of the production apparatus occurred just prior to January 1973; and, thus, the final sample of A-240 pitch (RD-131P) should aid in evaluating the effects of these changes. In addition, the vendor states that sources of crudes used in the warm weather months were geographically different from those obtained at other periods during the year.

Since feedstocks that are used to produce A-240 pitch are expected to show variability, this reproducibility study is, in essence, an evaluation of the pitch production process with regard to the ability to produce a consistent-response material from a variable-input material.

Evaluation of the Analytical Methods - In order to determine the reproducibility of the pitch, variability associated with the analytical methods was determined and a comparative study used to see. if the variability of the pitch was significantly greater than that attributable to the methods. Control studies consisted of a multiple analysis of sample $\mathrm{RD}-80 \mathrm{P}$ at various intervals during the analytical program. Data for the coritrol samples are included in Table 11. Control studies were not conducted on methods for determining viscosity and ash content, and data obtained for the nitrogen content were not analyzed due to the lack of a specific value for one data point. However, the latter analysis seemed quite variable. In general, the variability associated with many of the analytical methods would suggest that only larger variations in sample properties would be found to be significant relative to the control group. Methouds which were most reproducible were those used to determine the softening points and coke yields. Data obtained from NMR analyses were also quite reproducible. These facts are evident from the standard-deviation and coefficient-ofvariation values for the control group in Table 11. Methods for determining sulfur contents and average molecular weights are associated with only fair reproducibility, while the variability associated with methods for determining chloroform insolubles, benzene insolubles, oxygen contents, and nitrogen contents was much larger. Data obtained by GPC analysis on molecular size distributions showed adequate reproducibility with the exception of Fraction 1 (Table 11). This fraction corresponds to a low-molecular-weight species and could be influenced by: (1) a variable moisture content (which gives a negative detector response), (2) atmospheric gases which elute in this range, and (3) residual chloroform from the process used to remove insolubles prior. to analysis (see. Appendix A). Variability associated with chloroform insolubles would suggest that the method used to remove 
Table 11

PROPERTIES OF PETROLEUM PITCH A-240

\begin{tabular}{|c|c|c|c|c|c|c|c|c|c|c|c|c|c|c|c|c|c|c|c|}
\hline & \multirow[b]{2}{*}{$\begin{array}{c}\text { Sample } \\
\text { Number }\end{array}$} & \multicolumn{3}{|c|}{ Softening } & \multirow{2}{*}{$\begin{array}{c}\text { Chloroform } \\
\text { Insolubles } \\
(\%)\end{array}$} & \multirow{2}{*}{$\begin{array}{c}\text { Average } \\
\text { Molecular } \\
\text { Weight }\end{array}$} & \multirow{2}{*}{$\begin{array}{c}\text { Benzene } \\
\text { Insolubles (2) } \\
(\%)\end{array}$} & \multicolumn{4}{|c|}{ Composition of Molecular Distribution (3) } & \multirow{2}{*}{$\begin{array}{c}\text { Oxygen } \\
\text { Content } \\
(\%) \\
\end{array}$} & \multirow{2}{*}{$\begin{array}{c}\text { Nitrogen } \\
\text { Content } \\
(\%)\end{array}$} & \multirow{2}{*}{$\begin{array}{c}\text { Sulfur } \\
\text { Content } \\
(\%) \\
\end{array}$} & \multirow{2}{*}{$\begin{array}{c}\text { Ash } \\
\text { Content } \\
\text { (\%) }\end{array}$} & \multirow[b]{2}{*}{$\mathrm{H}_{A}^{*(4)}$} & \multirow[b]{2}{*}{$f_{a}{ }^{(4)}$} & \multirow[b]{2}{*}{$n^{(4)}$} & \multirow{2}{*}{$\begin{array}{c}\text { Coke } \\
\text { Yield } \\
(\%) \\
\end{array}$} \\
\hline & & $\begin{array}{c}\text { Month } \\
\text { Sampled }\end{array}$ & $\begin{array}{l}\text { Point } \\
\left({ }^{\circ} \mathrm{C}\right)\end{array}$ & $\begin{array}{c}\text { Viscosity(1) } \\
(\mathrm{sec})\end{array}$ & & & & $\begin{array}{c}\text { Fraction } 1 \\
\text { (\%) }\end{array}$ & $\begin{array}{c}\text { Fraction } 2 \\
(\%) \\
\end{array}$ & $\begin{array}{c}\text { Fraction } 3 \\
(\%)\end{array}$ & $\begin{array}{c}\text { Fraction } 4 \\
(\%)\end{array}$ & & & & & & & & \\
\hline \multirow[t]{13}{*}{ A-240 } & RD.58P & Jan '72 & 112.8 & $\cdot$ & 7.6 & 466 & 5.9 & 9.3 & 26.7 & 26.7 & 37.4 & 0.26 & 0.34 & 1.21 & 0.21 & 0.56 & 0.81 & 1.25 & 49.5 \\
\hline & RD-64P & Feb & 113.8 & 74 & 9.3 & 424 & 3.8 & 6.8 & 22.7 & 28.9 & 41.7 & 0.23 & $<0.03$ & 1.05 & 0.18 & 0.57 & 0.82 & 1.22 & 48.1 \\
\hline & RD-75P & Mar & 112.7 & 83 & 11.6 & 511 & 4.8 & 13.2 & 26.9 & 24.2 & 35.7 & 0.26 & 0.12 & 0.74 & 0.16 & 0.56 & 0.82 & 1.22 & 45.6 \\
\hline & RD-80P & Apr & 114.4 & 53 & 6.7 & 478 & 6.4 & 8.7 & 27.9 & 28.6 & 34.8 & 0.20 & $<0.03$ & 0.86 & 0.09 & 0.57 & 0.82 & 1.22 & 49.0 \\
\hline & RD-90P & May & 113.0 & 51 & 3.9 & 483 & 3.3 & 8.2 & 25.3 & 29.9 & 36.6 & 0.18 & $<0.03$ & 1.09 & 0.13 & 0.58 & 0.83 & 1.23 & 49.4 \\
\hline & RD-92P & Jun $(5)$ & 110.2 & 44 & 7.3 & 494 & 4.7 & b.6 & 24.0 & 30.0 & 30.3 & 0.22 & 0.11 & 122 & ก ก & 0.61 & 0.84 & 1,16 & 45.8 \\
\hline & RD-94P & Jun & 110.0 & 60 & 8.5 & 530 & 4.0 & 11.9 & 25.3 & 25.9 & 36.9 & 0.21 & 0.16 & 1.18 & 0.11 & 0.57 & 0.82 & 1.21 & 47.4 \\
\hline & RD-100P & Jul & 110.2 & 79 & 9.6 & 526 & 5.3 & 11.0 & 25.0 & 26.2 & 37.9 & 0.22 & 0.18 & 0.90 & 0.11 & 0.60 & 0.84 & 1.14 & 47.2 \\
\hline & RD-105P & Aug & 112.5 & 52 & 7.2 & 456 & 5.8 & 8.0 & 28.0 & 28.1 & 35.9 & 0.20 & 0.08 & 1.04 & 0.09 & 0.54 & 0.80 & 1.25 & 46.9 \\
\hline & RD-131P & Jan '73 & 110.5 & 45 & 11.1 & 422 & 6.0 & 8.0 & 27.3 & 26.3 & 38.4 & 0.19 & 0.10 & 1.09 & 0.17 & 0.54 & 0.82 & 1.28 & 46.4 \\
\hline & Mean & & 112.0 & 60 & 8.3 & 479 & 5.0 & 9.2 & 25.9 & 27.5 & 37.5 & 0.22 & & 1.04 & 0.13 & 0.57 & 0.82 & 1.22 & 47.5 \\
\hline & Standard Deviation & & 1.6 & 15 & 2.3 & 38 & 1.1 & 2.2 & 1.7 & 1.9 & 2.0 & 0.03 & & 0.16 & 0.04 & 0.02 & 0.01 & 0.04 & 1.4 \\
\hline & $\begin{array}{l}\text { Coefficient of } \\
\text { Variation }(\%)\end{array}$ & & 1.4 & 25.0 & 27.7 & 7.9 & 22.0 & 23.9 & 6.6 & 6.9 & 5.3 & 13.6 & & 15.4 & 30.8 & 3.5 & 1.2 & 3.3 & 2.9 \\
\hline \multirow[t]{3}{*}{ ' } & RD-80PA & & 114.4 & & 6.7 & 478 & 6.4 & 8.7 & 27.9 & 28.6 & 34.8 & 0.20 & $<0.03$ & 0.86 & & 0.57 & 0.82 & 1.22 & 49.0 \\
\hline & RD-80PB & & 111.5 & & 7.3 & 450 & 5.0 & 9.1 & 26.1 & 28.6 & 36.2 & 0.20 & 0.19 & 0.94 & & 0.56 & 0.82 & 1.25 & 48.2 \\
\hline & RD-80PC & & 111.5 & & 7.7 & 460 & 6.5 & 10.7 & 26.5 & 25.9 & 36.8 & 0.24 & 0.10 & 0.96 & 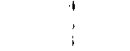 & 0.59 & 0.83 & 1.18 & 47.7 \\
\hline \multirow{6}{*}{$\begin{array}{l}\text { Control } \\
\text { Samples }\end{array}$} & RD-80PD & & 110.5 & & 11.0 & 510 & 5.3 & 10.2 & 26.0 & 26.7 & 37.1 & 0.23 & 0.05 & 0.95 & 1 & 0.60 & 0.84 & 1.20 & 48.9 \\
\hline & RD-80PE & & 115.2 & & 11.5 & 518 & - & 12.5 & 24.8 & 25.1 & 37.6 & 0.23 & 0.05 & 0.86 & $i$ & 0.58 & 0.83 & 1.23 & 48.2 \\
\hline & Mean & & 112.8 & & 8.8 & 183 & 5.8 & 10.2 & 26.3 & 27.0 & 36.5 & 0.22 & & 0.91 & $!$ & 0.58 & 0.83 & 1.22 & 48.4 \\
\hline & Standard Deviation & & 2.1 & & 2.2 & 30 & 0.8 & 1.5 & 1.1 & 1.6 & 1.1 & 0.02 & - & 0.05 & & 0.02 & 0.01 & 0.03 & 0.5 \\
\hline & $\begin{array}{l}\text { Coefficient of } \\
\text { Variation (6) (\%) }\end{array}$ & & 1.9 & & 25.0 & 6.2 & 13.8 & 14.7 & 4.2 & 5.9 & 3.0 & 9.1 & & 5.5 & & 3.4 & 1.2 & 2.5 & 1.0 \\
\hline & Variance Ratio (7) & & 1.6 & & 1.1 & 1.6 & 1.9 & 2.1 & 2.5 & 1.5 & 3.5 & 2.1 & & $10.2^{(8)}$ & & 2.0 & 2.2 & 2.4 & $6.9^{(8)}$ \\
\hline \multicolumn{20}{|c|}{$\begin{array}{l}\text { (1) Mcasured as Saybolt-Furnl secionds at } 200^{\circ} \mathrm{C} \text {. } \\
\text { (2) Determined as per Appendix A. } \\
\text { (3) Fractions correspond to elution count ranges on GPC scans (see Figure 2). } \\
\text { (4) Determined from NMR data as described in Appendix C. } \\
\text { (5) Two samples were processed in June. } \\
\text { (6) Standard deviation/mean } \times 100 \text {. } \\
\text { (7) Between control and total population (variance is the square of the standard deviation). } \\
\text { (8) Significant at confidence limit of } 0.95 \text {. }\end{array}$} \\
\hline
\end{tabular}


insolubles from the pitch prior to determinations of the average molecular weights and molecular size distributions was quite variable. How much variability in molecular size and weight data can be attributed to the process for removal of insolubles is not known.

Comparative Analysis of the Control Group with the Sample Population - Data collected for ten pitch samples that were received monthly are included in Table 11. Comparisons between the variability associated with these samples and that associated with the analytical method may be made by comparing the estimate-of-variance and coefficient-of-variation values of the sample population with those of the control group. Coefficient-of-variation values of the sample population were, for the most part, greater than those of the control group. In only one case (softening points) was it lower; and, for two other cases $\left(\mathrm{H}_{\mathrm{A}}^{*}\right.$ and $f_{a}$ ), it was essentially identical. However, of those that show differences, only two cases (sultur contents and coke yields) can be said to be statistically significant at the 95 percent coinfidence level. These exceptions are evident in Table 11 hy the high values for the variance ratios between the eamplo population and the control gruup (val iallce is the square of the standard deviation). Such ratios allow a test of significance at given confidence levels. Viscocity, ach oontent, and nitrogen-conteint values ful the sample populatlon seeméd quite variable, though lack of corresponding data on the control group prevented a comparative analysis.

The pitch sample (RD-92P) received in June 1972 was stated to be derived from a different crude source, and that received in January 1973 (RD-131P) followed considerable renovation to the facility. However, the properties of neither of these samples are significantly different from those represented by the sample population. Thus, the data suggest that month-to-month differences in pitch properties, for the most part, fall within the reproducibility limits of the analytical methods at the 95 percent confidence level, Though variability in the coke-yield values was statistically significant relative to the control group, the coefficicnt of variation was small $(2.9 \%)$ relative to that calculated for mnst nf the other samplc group properties.

Though not proven to be statistically significant, possible trends in the data may be more readily visualized by an examination of Figures 7 though 9 . Observations were as follows: (1) there was an apparent overall decrease in the softening point with increasing time (Figure 7); (2) average=molecular-woight valucs (Figure 7) inciedse (bul nul cunsistently) for the initial sevcn months (8 samples) of the study as do values for the conntrol samples which were analyzed during this same seven-month period; (3) values for the oxygen content, ash content, and coke yield apparenlly decreuse with time (Figure 8); (4) Figure 9 shows trends for the molecular-size-distribution data on the control samples, but none for the sample population. Values for Tractions 1 and 4 (Figure 9) increase with increasıng chronological sampling data, whils. Frantinns? nnd 3 decrease corresponidiryly.

Correlations between Pitch and Feedstock Properties - The petroleum pitches discussed in this report are recovered as distillate fractions during the pitch-production process, but should not be considered as just the higher-molecular-weight constituents that werc prcsent in the feedstock. Rather, a high percentage of the input feed is recovered as pitch. Thus, the pitch-production process is based on chemical change rather than mere fractionation; and, as such, would more dependent on molecular structural types that compose feedstock materials and less so on molecular size or weight distributions. Data collected on feedstock 


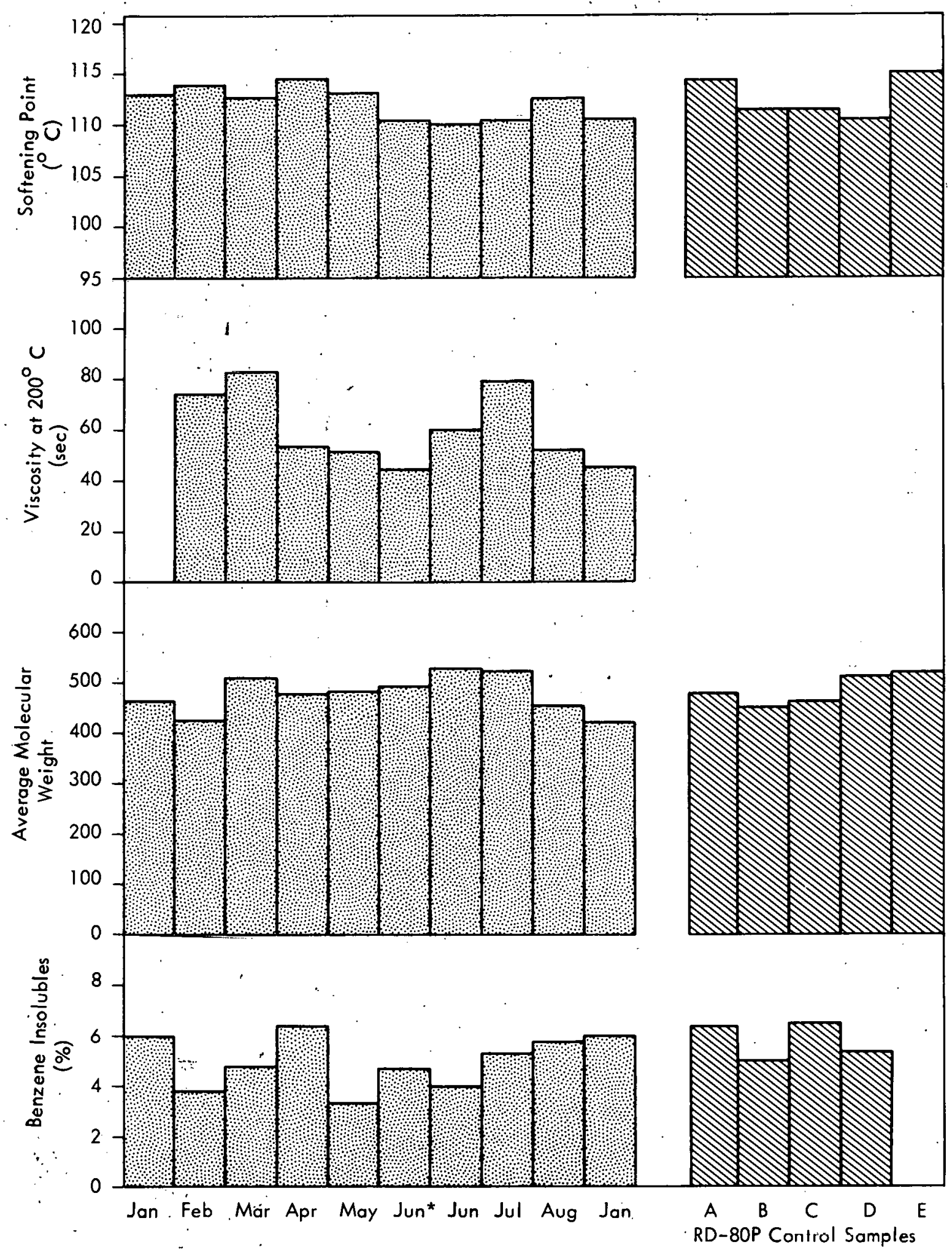

Figure 7. PROPERTIES OF PETROLEUM PITCHES AS FUNCTIONS OF THE SAMPLING PERIOD. 

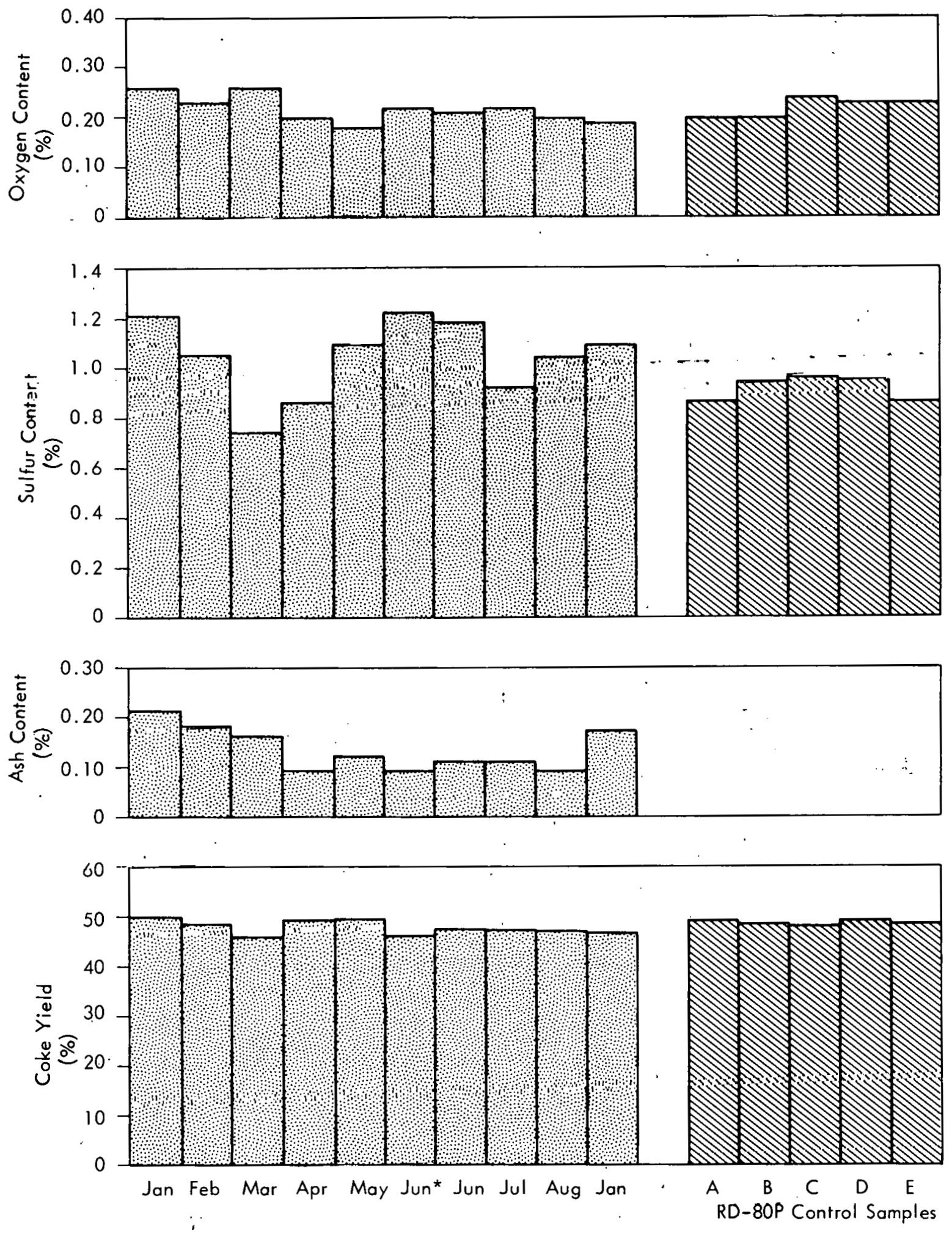

Figure 8. PROPERTIES OF TYPE A-240 PITCH AS FUNCTIONS OF THE SAMPLING PERIOD. 


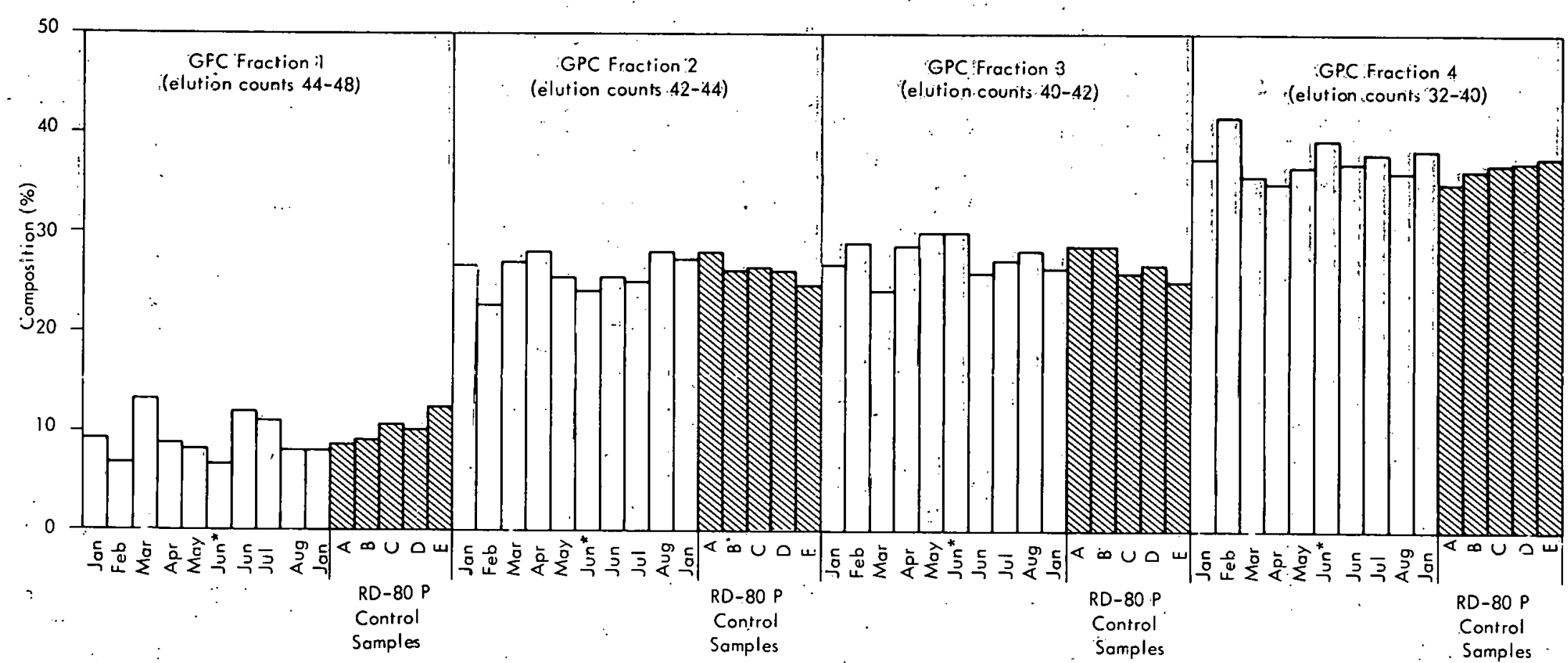

Figure 9. COMPOSITION OF PETROLEUM PITCH IN TERMS OF ITS MOLECULAR SIZE FRACTIONS. 
samples that correspond to the pitch samples in Table 11 are listed in Table 12. Coefficient-of-variation values show: (1) a high variability in viscosity data; (2) that the variability of the molecular size distribution data is generally greater than observed for the pitch sample population; (3) that variability of the molecular weight data was less than observed for pitch (possibly due to fact that no insolubles need be removed from feedstocks prior to analysis); (4) that data obtained from NMR measurements $\left(H_{A}^{*}, n, f_{a}\right)$ suggest that structural variations (aromatic-aliphatic distributions, substituent sizes) were greater in feedstocks than in pitches. The latter fact implies that month-to-month structural differences in the feedstocks are decreased or leveled somewhat during conversion to a pitch. Variability in the sulfur and ash contents of the feedstocks was similar to that of the pitches.

Figure 10 makes it pussible to visualize possible trends in feedstock properties with the sampling period. Ash contents decrease with the sampling period (as was previously ubserved for pitch samples) while sulfur valıes increase. This distinct trend in sulfur values is not transferred to pitches, as the latter show quite variable sulfur contents. Molecular size distribution data, as given in Figure 11, show no obvious trends.

Statistically significant correlations that were found to exist between feedstock and pitch properties out of over 100 variable pairs are listed in Table 13. Positive correlations indicate the tendency of a pair of variables to increase or decrease in value together, while a negative correlation indicates that one variable tends to increase while the other decreases. All of the positive correlations in Table 13 would be expected to be due to the respective property relationships. However, the negative correlation between the feedstock sulfur content and pitch softening point had not been established. Sulfur levels in pitch are comparable to those in feedstocks, suggesting that little sulfur was lost during the cracking operation.

Summary - Only sulfur contents and coke yields of the pitch properties measured had a month-to-month variability that was significantly greater than that assigned to the anlalytical methods. Samples received in June 1972 (RD-92P) and January 1973 (RD-131P), corresponding to changes in the source of crude and process equipment, respectively, were not significantly different from the sampling population. Properties of feedstocks were somewhat more variable than those of derived pitches, but very little correlation was found between the feedstock and pitch properties.

\section{CONCLUSIONS}

The following conclusions were reached as a result of this study:

1. Variability of $A 240$ over a pruduction year was somewhat less than that of the feedstock used to produce the pitch; and, for the most part, was not significantly different from the variability attributable to the analytical methods.

2. There was little correlation between the feedstnck and A-240 pitch properties.

3. Data based on the average properties indicate, that converting feedstock to $A-170$ pitch is accompanied by a significant increase (factor of 2 or greater) in the molecular size of the aromatic species, but results in a decrease in the size of the alkyl substituent groups 
Table.12.

PROPERTIES OF PETROLLEUM FEEDSTOCKS

\begin{tabular}{|c|c|c|c|c|c|c|c|c|c|c|c|c|c|c|}
\hline \multirow[b]{2}{*}{$\begin{array}{l}\text { Semple } \\
\text { Nứmb̈er }\end{array}$} & \multirow[b]{2}{*}{$\begin{array}{l}\text { Month } \\
\text { Sampled }\end{array}$} & \multirow[b]{2}{*}{$\begin{array}{l}\text { Viscosity }(1) \\
\text { (sec) }\end{array}$} & \multicolumn{4}{|c|}{ Composition of Molecular Size Distributions (2) } & \multirow{2}{*}{$\begin{array}{l}\text { Sulfur } \\
\text { Content } \\
(\%)\end{array}$} & \multirow{2}{*}{$\begin{array}{c}\text { Ash } \\
\text { Content } \\
(\%)\end{array}$} & \multirow[b]{2}{*}{$H_{A}^{*(3)}$} & \multirow[b]{2}{*}{$n^{(3)}$} & \multirow[b]{2}{*}{$f_{a}{ }^{(3)}$} & \multirow{2}{*}{$\begin{array}{c}\text { Carbon } \\
\text { Content } \\
(\%)\end{array}$} & \multirow{2}{*}{$\begin{array}{c}\text { Hydrogen } \\
\text { Content } \\
(\%)\end{array}$} & \multirow{2}{*}{$\begin{array}{c}\text { Averâge } \\
\text { Molecular } \\
\text { Weight } \\
\text { (\%) }\end{array}$} \\
\hline & & & $\begin{array}{c}\text { Fraction } 1 \\
(\%)\end{array}$ & $\begin{array}{c}\text { Fraction } 2 \\
\text { (\%) }\end{array}$ & $\begin{array}{c}\text { Fraction } 3 \\
(\%)\end{array}$ & $\begin{array}{c}\text { Fraction } 4 \\
(\%)\end{array}$ & & & & & & & & \\
\hline RD-59P & Jan 72 & 432 & 13.1 & 45.3 & 24.5 & 17.2 & 0.71 & 0.12 & 0.23 & 3.2 & 0.60 & 89.70 & 8.63 & 299 \\
\hline RD-65P & Feb & 189 & 15.5 & 48.5 & 22.5 & 13.5 & 0.76 & 0.10 & 0.26 & 2.7 & & & & \\
\hline RD-74P & Mar & 292 & 14.5 & 45.8 & 23.8 & 15.9 & 0.72 & 0.11 & 0.20 & 3.2 & & & & \\
\hline RD-79P & Apr & 327 & 13.8 & 43.1 & 24.4 & 18.7 & 0.67 & 0.08 & 0.23 & 3.0 & 0.59 & 89.77 & 8.99 & 301 \\
\hline RD-89P. & Mav & 122 & 12.6 & 50.6 & 21.7 & $15.1^{\circ}$ & 0.86 & 0.07 & 0.27 & 3.0 & & & .. & \\
\hline RD-91P & $\operatorname{Jun}^{(4)}$ & 154 & 16.1 & 50.4 & 21.7 & 11.8 & 1.06 & 0.07 & 0.32 & 2.4 & & & & \\
\hline RD-93P & Jun & 114 & 17.2 & 49.7 & 20.7 & 12.4 & 0.99 & 0.05 & 0.30 & 2.5 & 0.67 & 89.41 & 8.13 & 273 \\
\hline RD-99P & Jul & 158 & 13.2 & 51.2 & 24.3 & 11.3 & 1.13 & 0.05 & 0.26 & 2.6 & . & & & \\
\hline FD-130P & Jan'73 & 3010 & 8.5 & 49.1 & 30.8 & 11.5 & 1.05 & 0.07 & 0.31 & $2.7^{\circ}$ & 0.66 & 90.61 & 8.56 & 275 \\
\hline \multicolumn{2}{|l|}{ Mean } & 232 & 13.8 & 48.2 & 23.8 & 14.2 & 0.87 & 0.08 & 0.26 & 2.8 & 0.63 & 89.87 & 8.58 & 287 \\
\hline \multicolumn{2}{|c|}{ Standard Deviation } & 110 & 2.5 & 2.8 & 3.0 & 2.7 & 0.18 & 0.025 & 0.04 & 0.3 & 0.04 & 0.52 & 0.35 & 15 \\
\hline \multicolumn{2}{|c|}{$\begin{array}{l}\text { Coefficient of } \\
\text { Variation }(\%)(5)\end{array}$} & 47.4 & 18.1 & 5.8 & 12.6 & 19.0 & 20.7 & 31.3 & 15.3 & 10.7 & 6.3 & 0.6 & 4.1 & 5.2 \\
\hline
\end{tabular}

1) Measuied in Saybolt-Funol seconds at $25^{\circ} \mathrm{C}$.

2) Fractions correspond to elution count ranges on GPC scans (see Figure 2).

(3) Determined from NMR data as:described in Apfendix C.

(4) Two samples werz processed in June.

(5) Standard deviation/mean $\times 100$. 

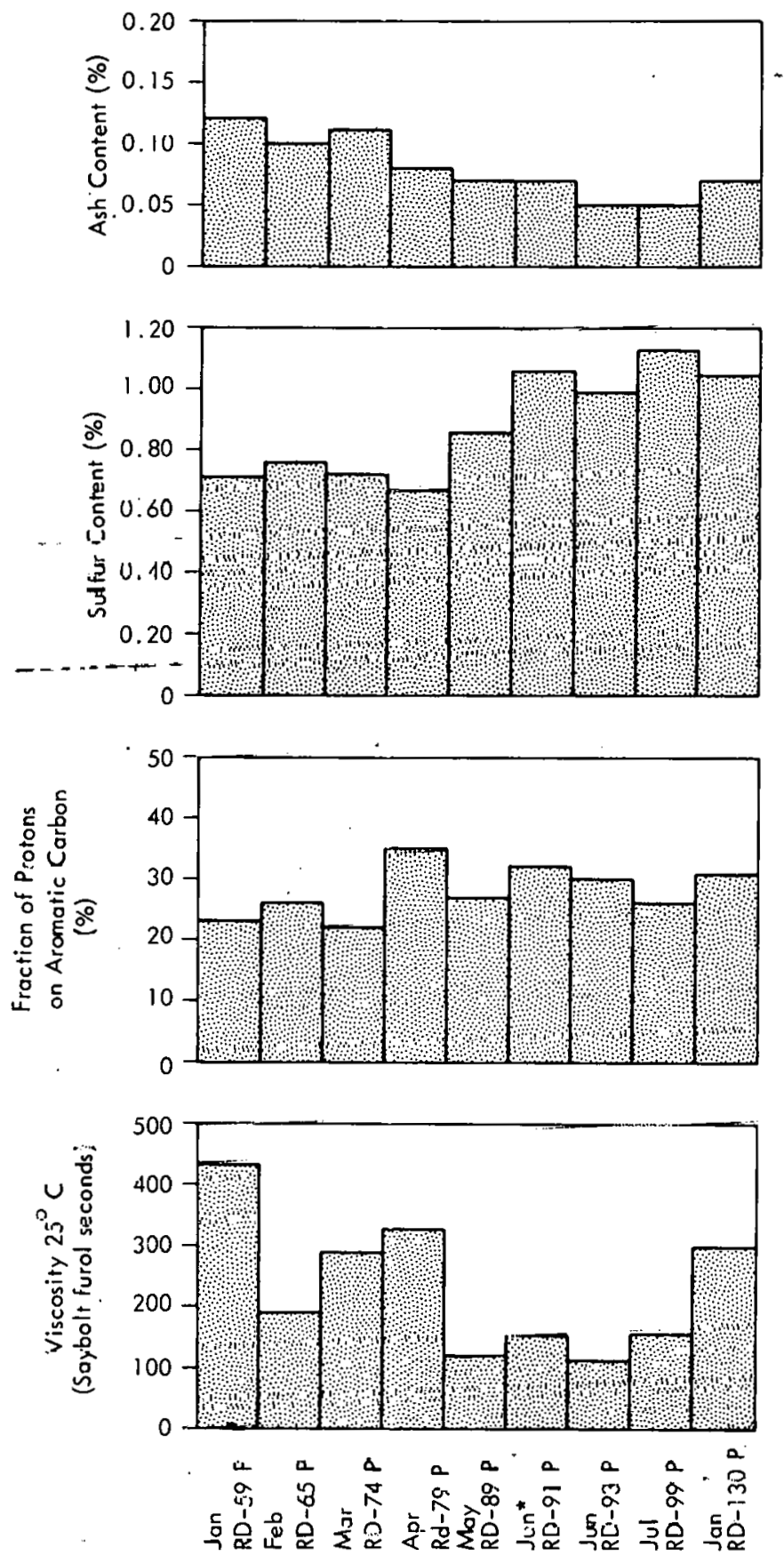

Figure 10. PROPERTIES OF PETROLEUM FEEDSTOCKS AS FUNCTIONS OF THE SAMPLING PERIOD.

by more than 50 percent. The number of substituents per molecule remains essentially constant $(\sim 3)$.

4. Fractionation studies suggest that the lower melting components of A-240 pitch have a higher aromatic composition with smaller alkyl substituent sizes, while the higher-melting species are less aromatic in composition and have significantly larger substituent groups. 


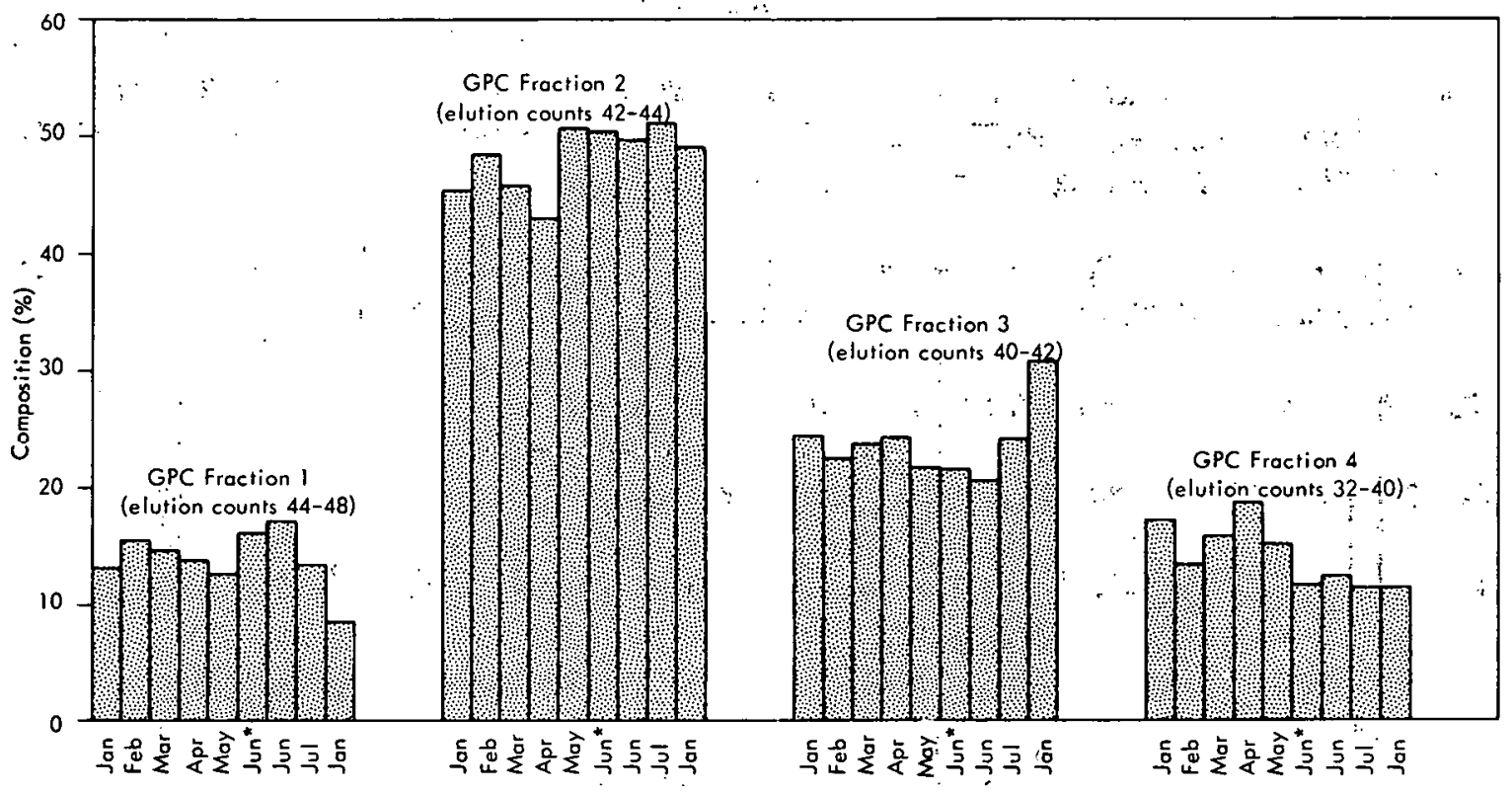

Figure 11. COMPOSITION OF PETROLEUM FEEOSTOCKS IN TERMS OF THEIR MOLECULAR SIZE FRACTIONS.

Table 13

CORRELATIONS BETWEEN PITCH AND FEEDSTOCK PROPERTIES

\begin{tabular}{lll}
\hline Feedstock Variable & Pitch Property & Correlations (1) \\
\hline Viscosity & Benzene Insolubles & Positive \\
GPC Composition 4 & Softening Point & Positive \\
Sulfur Content & Softening Point & Negative \\
Ash Content & Oxygen Content & Positive \\
Ash Content & Ash Content & Positive \\
\hline
\end{tabular}

(1) Lists only correlations that were statistically significant at the 95 percent confidence level.

5. Desulfurization of A-240 pitch decreases the ash content by a factor of 5 to 10 . There is an accompanying decrease in the oxygen content and a slight increase in the coke yield.

6. Desulfurization of A-240 pitch is accompanied by ring-opening reactions which, in addition to rings containing sulfur, include naphthenic and possibly aromatic structures. 


\section{REFERENCES}

(1) Horne, O. J. Jr, Smith, W. E., and Napier, B., Jr; Properties of Carbon Derived from Petroleum Pitches, Y-1875; Union Carbide Corporation-Nuclear Division, Oak Ridge Y-12 Plant, Oak Ridge, Tennessee; June 21, 197.3.

(2) Williams, R. B.; "Symposium on Composition of Petroleum Oils, Determination and Evaluation," ASTM Spec Tech Publication 224, pp 168-94 (1958).

(3) Williams, N. J.; Written Communication; Oak Ridge Y-12 Plant.

(4) Dorsey, J. G.; Written Communication; Oak Ridge Y-12 Plant.

(5) Clutter, D. R., et al; Analytical Chemistry, 44, pp 1395-1405 (1972). 


\section{ACKNOWLEDGEMENTS}

The authors wish to express their gratitude to C. Hoertz, D. Chapman, and J. W. Newman of the Petroleum Research Laboratory. of Ashland Oil for their cooperation in sampling and shipping the various products requested. Thanks are also expressed to personnel of the Y-12 Plant Analytical Laboratory for their special efforts during this study. 


\section{APPENDIX A}

\section{PROCEDURE FOR REMOVING INSOLUBLES FROM PITCHES}

The following procedure was used to remove insolubles from A-240 and A-170 pitches prior to GPC and average-molecular-weight determinations:

1. Weigh two 0.5 -gram aliquots of powdered pitch into $500-\mathrm{ml}$ boiling flasks having ground-glass joints.

2. Add $200 \mathrm{ml}$ of chloroform to each flask.

3. Using water condensers, reflux for $11 / 2$ hours.

4. Transfer the contents to $400 \mathrm{~m}$ I beakers and evaporate to dryness at room temperature.

5. Add $200 \mathrm{ml}$ of chlornform to the dricd samples and again ovaporatc to diyliess dit room lemperature.

6. Add $200 \mathrm{ml}$ chloroform to the dried samples and agitate thoroughly.

7. Filter the samples through a tared, fine-porosity, fritted glass funnel using Teflon for the seal between the funnel and the vacuum flask.

8. Rinse each beaker and funnel with $50 \mathrm{ml}$ of chloroform.

9. Dry the fritted funnels containing the insolubles at $50^{\circ} \mathrm{C}$ under house vacuum for 30 minutes, then cool in a desiccator, and weigh. Calculate the percent chloroform insolubles, reporting the average of the twn aliquots:

10. Transfer the filtrate to $400-\mathrm{ml}$ beakers and evaporate the contents to dryness at room temperature under house vacuum.

11. Use liquid nitrogen to break up the dry, chloroform-şoluble pitch.

12. Transfer to sample glass bottles and dry. uvernight at room temperature under house vacuum: 


\section{APPENDIX B}

STANDARDIZED INSTRÜMENT CONDITIONS FOR NUCLEAR MAGNETIC RESONANCE ANALYSES

The instrument conditions used for NMR analyses were as follows:

Concentration

Standard (internal)

Temperature

Time Constant

Sweepwidth $(+)$

Sweep Time

Offset

Attenuation
$5 \%$ in $\mathrm{CCl}_{4}$

TMS (tetramethylsilane)

$55^{\circ} \mathrm{C}$

$0.25 \mathrm{sec}$

$20 \mathrm{~Hz} / \mathrm{cm}$

$500 \mathrm{sec}$

0

60

45 


\section{APPENDIX C}

\section{CALCULATIONS USED FOR EVALUATING NUCLEAR MAGNETIC RESONANCE DATA}

Following the method described by Williams, ${ }^{(2)}$ and further discussed by Clutter, et al, (5) NMR data were evaluated by using proton distributions, average molecular weights, and elemental compositions to arrive at the properties listed in Table C-1. Major assumptions which were made in using this approach are:

1. That saturates are present only as substituents on aromatic nuclei and that aromatic nuclẹi in a given molecule are directly joined with no intervening alkyl group.

2. That the carbon/hydrogen ratio of the $a$-alkyl groups is equal to that of the other alkyl groups.

3. That the carbon/hydrogen ratio of the "total alkyl" groups can be accurately estimated.

According to the data in this report, the first assumption appears valid for this study. Williams states that the second assumption probably causes least concern, based upon an analysis of known compounds. The third assumption involved the determination of a "branchiness index" directly from proton spectra.

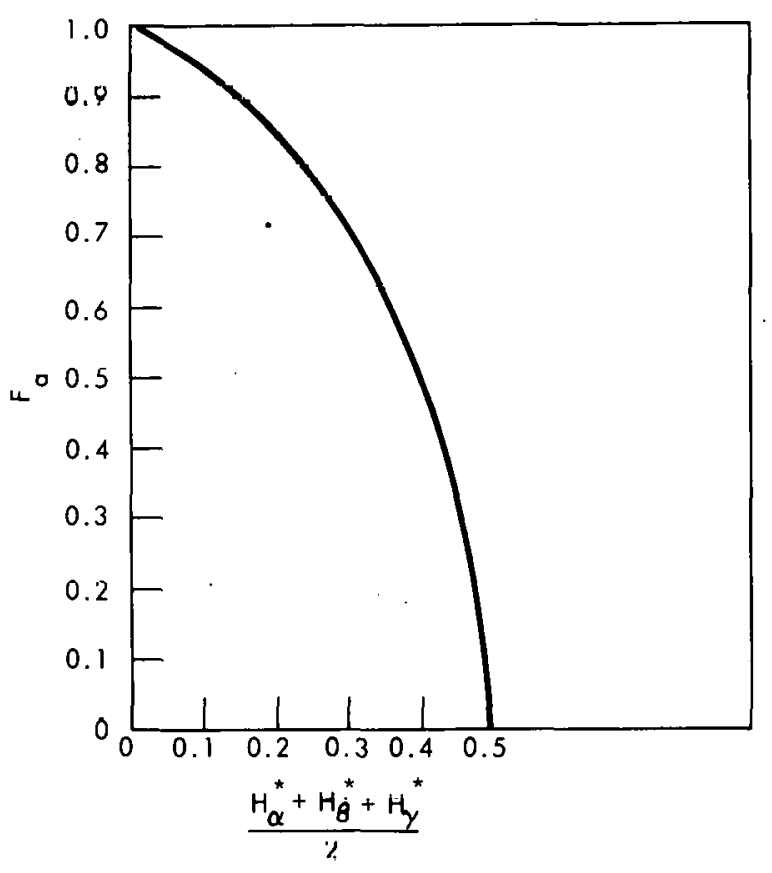

Figure C.1. CORRELATION OF AROMATICITY $\left(f_{g}\right)$ AND NORMALIZED INTENSITY OF THE ALKYL PROTONS OF PETROLEUM FRACTIONS.

A second approach to estimations of the aromaticity $\left(f_{a}\right)$ values involves a graphical solution using the graph of Figure $C \cdot 1$. This approach requires a knowledge of the proton distribution only and is used when resolution of NMR spectra is not sufficient to provide the detailed information necessary for the calculations of Table C-1. For this reason, aromaticity values for A-240 pitches were determined using the graphical approach. 
Table C-1

TERMS AND EQUATIONS FOR EXPRESSING NUCLEAR MAGNETIC RESONANCE DATA

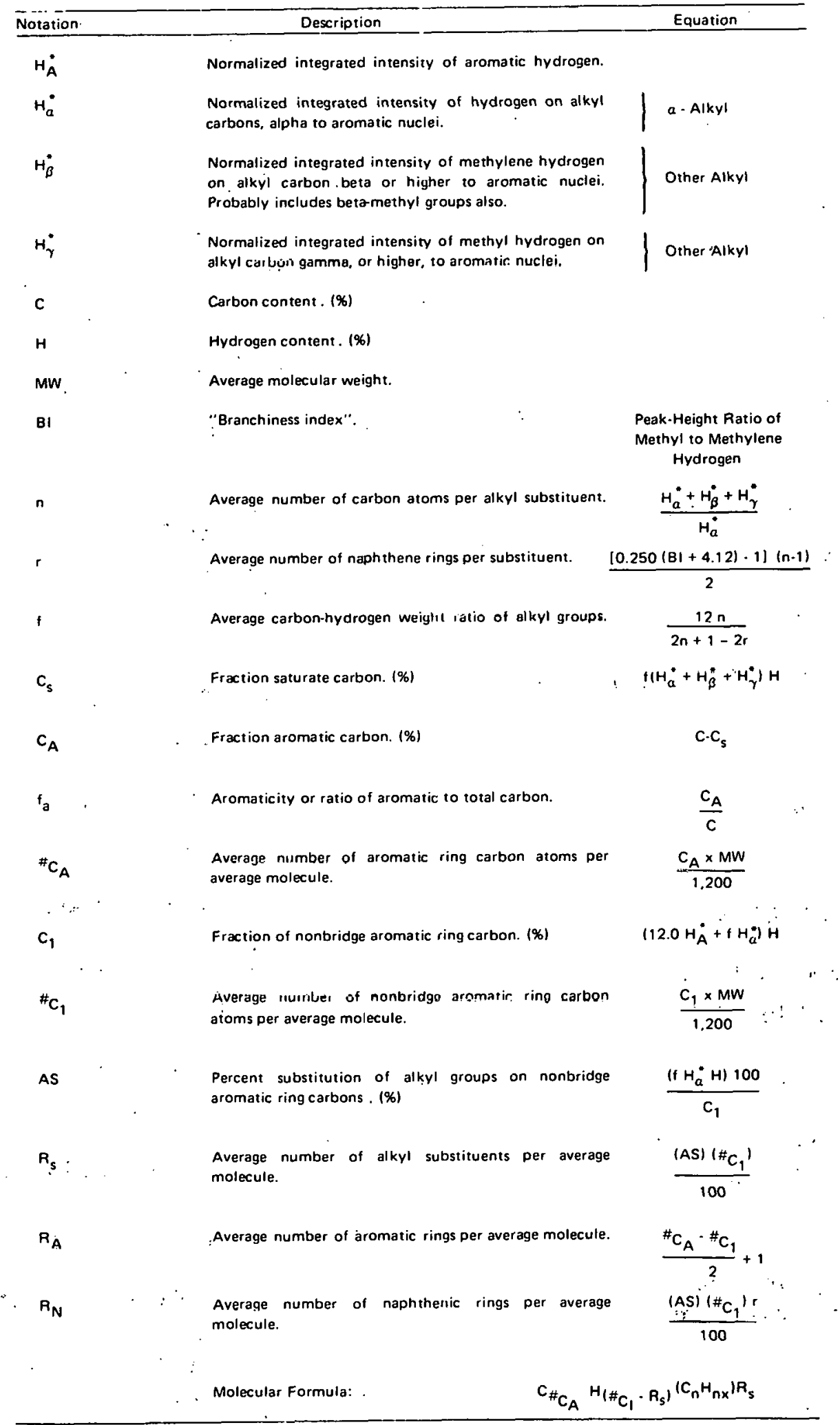




\section{DISTRIBUTION}

\section{Aerojet - General}

Swope, L. S.

Aerospace Corporation - El Segundo

Blaes, H. M., II

McDonald, W. R.

Meyer, R. A.

Aerospace Corporation - Los Angeles

Barry, W. T.

McClelland, J. D.

Arnyy Materlals and IMechanics Research Center

Dignan, J. F.

Ashland Oil and Refining Company.

Chapman, D.

Hoertz, C.

Newman, J.W.

Atomic Energy Commission - ORO

Hickman, H. D.

Zachry, D. S., Jr

Defense Nuclear Agency

Atkins, M./DDST

Jackson, $R$.

Moulton, J./APAS

Department of the Navy

Stoessl, L./SPR-27201

Director of Defense Research and Engineering

Persh, J.

Fiber Màterials, Inc

Lachman, W.

General Electric - Reentry and

Environmental Systems Division

Hall, K.

Musikant, S.

Stover, E. R.
Great Lakes Research Corporation

Whittaker, M. P.

Gulf - General Atomic

Engle, G. B.

Lawrence Livermore Laboratory

Kruger, $\mathrm{H}$.

Lockheed Missile and Space Company

Vidoz, A.

Los Alamos Scientific Laboratory

Williams, J. M.

McDonnell-Douglas Astronautics

Company

Arne, $C$.

Eitman, D.

NASA - Ames Research Center

Lundell, J. H.

Naval Air Systems Command

Schmidt, R.

Naval Ordinance Laboratory

Barnet, F. R./Kaubek, F. J.

Gowen, L/Code 2302

Rester, D. O.

Naval Ordinance Systems Command

Kinna, M. A./ORD-0333A

Oak Ridgr: Faseous Diffusion Plant

Wilcox, W. J., Jr

Winkel, R. A.

Oak Ridge National Laboratory

Bradley, R.

Eatherly, W. P.

Ferguson, D. E.

Scott, J. L. 
Strehlow, R. A.

Weir, J. R.

Oak Ridge Y-12 Plant

Ardary, Z. L.

Briscoe, O. W.

Burditt, R. B.

Burkhart, L. E.

Denny, A.

Horne, O. J., Jr (2)

Keith, Alvin

Kite, H. T.

Lambdin, F.

Lundin, M. I.

Marrow, G. B.

McLendon, J. D.

Napier, B., Jr (2)

Napier, J. M.

Overholser, L. G.

Phillips, L. R.

Pollock, C. B.

Schreyer, J. M.

Smith, R. D.

Smith, W. E. (5)

Tench, F. M.

Valentine, $K$.

Weathersby, W. E.

Williams, R. D.

Yaggi, W. J.

Y-12 Central Files (5)

$Y-12$ Central Files (master copy)

$Y-12$ Central Files (route)

Y-12 Central Files (Y-12RC)

Paducah Gaseous Diffusion Plant

Levin, R. W.

Penn State University

Walker, P. L., jr
Quaker Oats Company - John Stuart

Research Laboratory

Brown, L. H.

Watson, D.

\section{SAMSO}

Green, G./RSF

Mentzer, D./RSSR

Shover, D./RSSE

Sandia - Albuquerque

Auerbach, 1.

McDonald, J. E.

Peurifoy, R. L., Jr

Zimmerman, J. C.

Sandia - Livermore

Rychnovsky, R. E.

Union Carbide Corporation - Carbon Products Divsion

Browning, J. B.

Singer, $L$.

Townsend, H. N.

Union Carbide Corporation - Chemical and Plastics Division

Shechter, L.

University of Washington

Fishbach, D. B.

Wright-Patterson Air Forcc Base

Materne, H. A.

Pratt, C./MAAS

Schmidt, D./LNC

In addition, this report is distributed in accordance with the category UC-4, Chemistry, as given in the USAEC Standard Distribution Lists for Unclassified Scientific and Technical Report, TID.4500. 